\title{
Joining of Alumina \\ VIA \\ COPPER/Niobium/COPper INTERLAYers
}

\author{
Robert A. Marks, Daniel R. Chapman, David T. Danielson and Andreas M. Glaeser \\ Department of Materials Science and Mineral Engineering, \\ University of California \\ $\&$ \\ Center for Advanced Materials \\ Lawrence Berkeley National Laboratory, Berkeley, CA 94720
}

\begin{abstract}
Alumina has been joined at $1150^{\circ} \mathrm{C}$ and $1400^{\circ} \mathrm{C}$ using multilayer copper/niobium/copper interlayers. Four-point bend strengths are sensitive to processing temperature, bonding pressure, and furnace environment (ambient oxygen partial pressure). Under optimum conditions, joints with reproducibly high room temperature strengths $(\approx 240 \pm 20 \mathrm{MPa})$ can be produced; most failures occur within the ceramic. Joints made with sapphire show that during bonding an initially continuous copper film undergoes a morphological instability, resulting in the formation of isolated copper-rich droplets/particles at the sapphire/interlayer interface, and extensive regions of direct bonding between sapphire and niobium. For optimized alumina bonds, bend tests at $800^{\circ} \mathrm{C}-1100^{\circ} \mathrm{C}$ indicate significant strength is retained; even at the highest test temperature, ceramic failure is observed. Postbonding anneals at $1000^{\circ} \mathrm{C}$ in vacuum or in gettered argon were used to assess joint stability and to probe the effect of ambient oxygen partial pressure on joint characteristics. Annealing in vacuum for up to $200 \mathrm{~h}$ causes no significant decrease in room temperature bend strength or change in fracture path. With increasing anneal time in a lower oxygen partial pressure environment, the fracture strength decreases only slightly, but the fracture path shifts from the ceramic to the interface.
\end{abstract}




\section{INTRODUCTION}

Ceramic-metal interfaces are a critical feature in many materials systems, and processing of these interfaces is fundamental to fabrication of a wide range of materials and devices. Of the numerous methods available for ceramic-ceramic and ceramic-metal joining, solid-state diffusion bonding and reactive metal brazing have been most heavily investigated for producing reliable joints for demanding high-stress, hightemperature applications [1-5]. Diffusion bonding and brazing have unique advantages, but also liabilities that increase in number and severity as processing temperatures are increased. Since diffusion bonding (brazing) temperatures generally approach (exceed) the intended use temperature, microstructural degradation during joining becomes an increasingly important issue as joining temperatures increase. Greater attention must also be paid to chemical compatibility of the components to be joined with one another and the joining media. Incompatibilities that are absent or mitigated by sluggish reaction kinetics at low temperature manifest themselves more obviously when joints are produced at elevated temperature. As a result of these complications, the technology for producing refractory joints is not as well developed as that for low-temperature joints.

Over the past thirty years, numerous approaches designed to develop refractory joints by means of low-temperature processes have been explored. Efforts were made to extent transient liquid phase (TLP ${ }^{\mathrm{TM}}$ ) methods for joining nickel-base superalloys to the joining of silicon nitride [6-13] and silicon carbide [14, 15] ceramics. Multilayer interlayers combining lower and higher melting point metals that would homogenize by solid-state diffusion were proposed as alternatives to the homogeneous metallic interlayers normally used for solid-state diffusion bonding [16]. Joining methods utilizing multilayer metallic interlayers under conditions where a thin or partial layer of a transient liquid phase forms were also proposed $[17,18]$. The partial transient liquid phase (PTLP) method has been used to join oxide [18-23] and nonoxide ceramics [21-26].

Prior work exploring the use of multilayer copper/niobium/copper interlayers for the joining of alumina [20] demonstrated that strong joints could be produced at $1150^{\circ} \mathrm{C}$, well below the temperatures normally used for solid-state diffusion bonding of niobium to alumina. The limited solubility and slow 
diffusion of copper in niobium prevented disappearance of the liquid phase at the joining temperature. However, it was observed that the initially continuous copper film evolved into discrete copper-rich particles during processing; liquid-phase assisted growth of contact regions between niobium and alumina had apparently occurred. The present work is part of a broader effort to examine the effects of processing conditions on joint properties and to establish fundamental processing-microstructure-property relationships. The results demonstrate that under appropriate conditions, interfacial microstructures that yield reproducible strengths at both room and elevated temperature $\left(800-1100^{\circ} \mathrm{C}\right)$ can be attained.

\section{BACKGROUND}

The approach to bonding explored uses a multilayer metallic interlayer. Both of the ceramic surfaces to be joined are coated with a thin cladding layer of a low melting metal, copper in this case. A thick core layer of a high melting point metal, niobium in this study, is inserted between the coated alumina surfaces. At the bonding temperature, $1150^{\circ} \mathrm{C}$ or $1400^{\circ} \mathrm{C}$, the cladding layers melt, while the core layer remains solid. As a result, a thin liquid layer forms between the ceramic and core layer. The sum of the contact angles of the liquid on the ceramic, $\theta_{1}$, and on the core metal, $\theta_{2}$, must be less than $180^{\circ}$ to promote void filling and thinning of the liquid film. With increasing time at temperature, discrete copperrich particles, and thus, regions of niobium/alumina and copper/alumina bonding, develop along the alumina/interlayer interface. As a result, the properties of the joined assemblies reflect the properties of niobium/alumina interfaces, copper/alumina interfaces, and the wetting behavior of a copper-rich liquid on both niobium and alumina. Prior work addressing these topics is reviewed.

\section{Prior Work on Niobium/Sapphire Interfaces}

The niobium/sapphire system has been a model metal/ceramic system for nearly thirty years due to the excellent thermal expansion match between the two materials, their high melting temperatures, and the absence of severe chemical interaction. The diffusion bonding of these materials, their interfacial structure, chemical compatibility, strength and failure characteristics, and the influence of interfacial impurities have all been examined and reported extensively in the literature. 


\section{Diffusion Bonding Conditions and Joint Properties}

Diffusion bonding of sapphire or alumina to niobium has been performed over a wide range of time-temperature-bonding load conditions. Generally, for conventional high vacuum $\left(\mathrm{HV} ; \approx 10^{-3} \mathrm{~Pa}\right)$ diffusion bonding, studies have focussed on the temperature range $1500-1950^{\circ} \mathrm{C}$, with bonding times of several hours, and a bonding load typically of the order of $10 \mathrm{MPa}$ [27-31]. Bonding temperature reductions of up to $500^{\circ} \mathrm{C}$ relative to $\mathrm{Hv}$ bonding can be achieved by the use of ultrahigh vacuum (UHV; $\approx 10^{-8} \mathrm{~Pa}$ ) conditions coupled with sputter cleaning of the bonding surfaces [32]. However, in both HV and uHV bonds, fracture energies increase with increasing bonding temperature, a trend attributed to an increase in the area fraction bonded. ${ }^{\dagger}$ As a result, "typical" uHv bonding conditions for niobium/sapphire involve $3 \mathrm{~h}$ at $1400^{\circ} \mathrm{C}$ with an applied load of $10 \mathrm{MPa}$; these conditions allow the fabrication of wellbonded couples with high fracture energies.

Mechanical tests of both bicrystal joints and polycrystalline niobium/polycrystalline alumina joints have provided fracture energy $\left(G_{c}\right)$ values. Samples in which oriented sapphire and oriented niobium single crystals are bonded show that $G_{c}$ is very sensitive to the interface crystallography with values ranging from $\approx 60[35]$ to $\approx 2400 \mathrm{~J} / \mathrm{m}^{2}[36]$ in room temperature tests. For most crystallographies, the failures are interfacial. Bonds involving polycrystals typically undergo interfacial failure, and exhibit either lower fracture energies [37], or fracture energies nearer to the lower bicrystal values [36]. A limited number of strength measurements indicate that joints processed at $1600^{\circ} \mathrm{C}$ under $\mathrm{HV}$ conditions fail at stresses of the order of 100-150 MPa [27, 29].

\section{Dissolution of Alumina; Oxygen and Aluminum Diffusion}

Although niobium does not reduce alumina, alumina dissolves at the niobium/alumina interface and both oxygen and aluminum diffuse into the adjoining niobium $[28-32,38,39]$. The equilibrium oxygen levels in initially pure niobium due to alumina dissolution increase with temperature, and are predicted to be of the order of 0.07 at $\%$ at $1000^{\circ} \mathrm{C}$ and $\approx 1$ at $\%$ at $1600^{\circ} \mathrm{C}[40]$ assuming that there is no loss of oxygen or

\footnotetext{
${ }^{\dagger}$ The clearest demonstration of this is found in the work of Gibbesch and Elssner [33]. Gibbesch et al. [34] have compared the fracture energy of UHV and $\mathrm{HV}$ diffusion bonded niobium/alumina joints, and results indicate that equivalent $\mathrm{G}_{\mathrm{c}}$ values can be obtained at $\approx 300^{\circ} \mathrm{C}$ lower bonding temperature when the UHV environment and sputter cleaning are used. Korn et al. cite an $\approx 200^{\circ} \mathrm{C}$ reduction in processing temperature when equal bonding pressures are used [35].
} 
aluminum to the ambient. The hardness and yield stress of niobium increase approximately linearly with oxygen content [41], ${ }^{+}$and bonds produced at $\geq 1600^{\circ} \mathrm{C}$ (or that use niobium intentionally doped with oxygen [42]) have undesirable properties [29].

Aluminum diffuses substitutionally in niobium, while oxygen diffuses by an interstitial mechanism. At $1000^{\circ} \mathrm{C}$ and $1400^{\circ} \mathrm{C}$, the oxygen diffusivity $[43,44]$ to aluminum diffusivity [45] ratio is of the order $10^{8}$ to $10^{5}$, respectively, and thus, the relative diffusion distance for oxygen is much greater, especially at lower temperatures. A simplified theoretical model, assuming independent diffusion of aluminum and oxygen within niobium (and no loss of either specie), and no solubility limit for aluminum or oxygen has been developed to predict the compositional profiles of aluminum and oxygen in niobium [46]. Predicted nearinterfacial aluminum levels are of the order 10-12 at\% over a wide bonding temperature range. Experimental values are a factor of 4-6× lower, largely due to recondensation and precipitation during cooling. Transmission electron microscopy studies $[28,31,38,39]$ show that $\theta$-alumina precipitates can form in the near-interfacial region, and that alumina can also condense at interfacial flaws, with the details of the evolution sensitive to cooling rate $[38,39]$. Thermodynamic considerations [47] indicate that the initial oxygen (or aluminum) content of the niobium and the ambient oxygen pressure will have a substantial influence on the dissolution, and thus, the near-grain boundary chemistry during bonding.

\section{Role of Interfacial Impurities}

Fracture in niobium/sapphire and niobium/alumina couples is generally interfacial. Thus, impurities that segregate to this interface can affect the resulting fracture strength directly through their effect on interfacial adhesion, and indirectly through the effect of adhesion on plastic dissipation accompanying fracture. Korn et al. [35] and Elssner et al. [48] examined the influence of interface impurities (Ag, S, Ti) on the fracture energy of unv bonded niobium/sapphire bicrystals prepared at $1400^{\circ} \mathrm{C}$. Submonolayer to nanometer thick layers of silver were found to yield a segregation profile and decrease the fracture energy, $\mathrm{G}_{\mathrm{c}^{+}}$Segregation of sulphur, present as an impurity at a $30 \mathrm{ppm}$ level in the niobium, was

\footnotetext{
+ At bonding temperatures above $\approx 1600^{\circ} \mathrm{C}$, the compositions of oxygen-doped niobium samples relax to a near-equilibrium value within typical bonding times, and as a result, the joint properties are "independent" of the initial oxygen level [40]. At lower temperatures, and in other studies, the deleterious role of excessive oxygen levels has been demonstrated clearly [42].
} 
detected at niobium/vapor interfaces after anneals at $1400^{\circ} \mathrm{C}$. When foils with sulphur segregant were used to prepare bonds, segregation at the niobium/sapphire interface was negligible, and changes in $\mathrm{G}_{\mathrm{c}}$ were small (within experimental error). In contrast, titanium substantially increases $G_{c}$; increased interfacial adhesion increases the contribution of plasticity to the work of fracture [48].

Tantalum and oxygen are common impurities in niobium [49]. Tantalum and niobium form complete solid solutions [50], and pure tantalum has a higher surface energy than pure niobium [51]. Thus, tantalum segregation to the surface is expected to be minimal. Oxygen can play multiple roles. It hardens niobium, and thus can reduce the contribution of plasticity to the work of failure. It can segregate to the interface, and influence interfacial adhesion directly (and thereby the plasticity contribution), or it can interact with other impurities [43] and modify their interaction with the niobium/sapphire interface. In the case of niobium/sapphire couples, dissolution of alumina at elevated temperature will add aluminum to the near-interfacial region, and will add to the initial oxygen content. Since oxygen diffusion in niobium is rapid, adjustments of the dissolved oxygen content can occur in regions of the interlayer within a diffusion distance of the surface due to oxygen exchange with the furnace atmosphere.

\section{Elimination of Interfacial Porosity}

Gibbesch and Elssner [33] bonded polycrystalline alumina using $2 \mathrm{~mm}$ thick, 99.99\% pure niobium plates under uHv conditions; the applied pressure was $10 \mathrm{MPa}$ and temperature was varied from $900^{\circ} \mathrm{C}$ to $1500^{\circ} \mathrm{C}$. The area fraction bonded increased with increasing bonding temperature. Plastic deformation of the metal was cited as the dominant mechanism of pore closure at the interface.

The morphological evolution of interfacial porosity during diffusion bonding of niobium and alumina at $\approx 1450^{\circ} \mathrm{C}$ was also examined by Reimanis [52]. Sapphire single crystals of two different orientations were bonded to (111)-textured 100-200 $\mu$ m thick $99.9 \%$ pure niobium foils under an applied pressure of $2 \mathrm{MPa}$, and pore removal at the interface was monitored using optical microscopy. Key findings of the study were that: 1) pore removal proceeded by the growth of highly facetted bonding fronts whose facet structure was related to the orientation of niobium grains, 2) pore removal rates in samples annealed with and without a $2 \mathrm{MPa}$ pressure were similar, and 3) that grain boundary grooves in the niobium foil appeared to provide the initial contact points with the sapphire, and played a key role in the development of 
new bonded regions. Significant unbonded regions persisted even after $18 \mathrm{~h}$ at $1450^{\circ} \mathrm{C}$, It is possible that the combined effects of different niobium thickness, purity, and applied pressure yielded different relative contributions of plasticity and diffusion to pore closure.

\section{Prior Work on Copper/Sapphire Interfaces}

\section{Diffusion Bonding Conditions and Joint Properties}

Several studies of diffusion bonding of alumina or sapphire using copper interlayers have been reported [32, 33, 53-57]. Most earlier work was conducted under HV conditions, while more recent work has included UHV bonding studies. In general, both $\mathrm{HV}$ and uHV bonding temperatures are in the range of 900-1050 ${ }^{\circ} \mathrm{C}$, with bonding times of $0.25-6 \mathrm{~h}$ and applied pressures in the range of 1-50 MPa. Several studies examined the effects of bonding temperature, pressure, and time on the area fraction bonded, and/or fracture strength $[33,54,55,57]$. Results suggest that samples diffusion bonded for periods of a few hours (or less) at temperatures $\geq 900^{\circ} \mathrm{C}$ with bonding pressures of $\leq 10 \mathrm{MPa}$ yield interfaces with high fractions of bonded area $[33,55,57]$; creep of the copper plays a key role in pore removal $[53,55,57]$.

Reported strength values for copper/alumina interfaces vary substantially ( 0 to $\approx 180 \mathrm{MPa}$ ) reflecting differences in processing conditions (interface microstructure), sample geometry, and test method. Measurements by Gibbesch and Elssner [33] suggest that copper/alumina (polycrystal) interfaces have a higher fracture energy than niobium/alumina (polycrystal) interfaces. Bicrystals yield $\mathrm{G}_{\mathrm{c}}$ values in the $100-200 \mathrm{~J} / \mathrm{m}^{2}$ range, however, results for only one misorientation have been reported [57]. Fracture energies are particularly sensitive to the presence of oxygen and the formation of phases at the metal/ceramic interface, as will be discussed shortly.

\section{Brazing using Copper-Cuprous Oxide Eutectic and Joint Properties}

Most studies of the wetting behavior of "pure" copper on alumina or sapphire indicate obtuse contact angles varying between $110^{\circ}$ and $170^{\circ}[20,22,55,58-64]$, with more limited evidence suggesting that the contact angle decreases slightly with increasing temperature $[59,62,63]$. The copper-oxygen phase

\footnotetext{
* Morozumi et al. [27] report $\approx 50 \%$ bonded area after $1 \mathrm{~h}, 8.8 \mathrm{MPa}$, $\mathrm{Hv}$ bonding at $1600^{\circ} \mathrm{C}$. Turwitt et al. [37] report that after a $2 \mathrm{~h}, 10 \mathrm{MPa} \mathrm{Hv}$ bonding cycle at $1700^{\circ} \mathrm{C}, \approx 10-20 \%$ of the interface remains unbonded, suggesting that porosity removal is slow even at substantially higher temperature. In contrast, Gibbesch and Elssner [33] report $\approx 98 \%$ bonded area after $1 \mathrm{~h}, 10 \mathrm{MPa}$ uHv bonding at $1600^{\circ} \mathrm{C}$.
} 
diagram contains a copper-cuprous oxide $\left(\mathrm{Cu}_{2} \mathrm{O}\right)$ eutectic at $1066^{\circ} \mathrm{C}$. As the oxygen solubility limit of copper at $1066^{\circ} \mathrm{C}(\approx 0.03$ at $\%)$ is exceeded, a eutectic liquid forms. At higher temperatures $\left(\approx 1092^{\circ}\right.$ $\left.1200^{\circ} \mathrm{C}\right)$, oxygen additions can also reduce the contact angle $[55,60,61,64]$, and the wetting behavior of copper on sapphire or alumina has been examined over a wide range of ambient oxygen partial pressure [60, $61,64]$. At sufficiently high oxygen potentials, contact angles as low as $\approx 10^{\circ}$ have been observed [55]. Several investigations have attempted to correlate the mechanical properties of such eutecticbonded alumina with oxygen content and bonding time [e.g., 65, 66]. Oxygen diffuses rapidly in solid copper $[44,67-70]$, with reported diffusivities at $1000^{\circ} \mathrm{C}$ ranging from $\approx 1.4 \times 10^{-5}$ to $\approx 3.1 \times 10^{-5} \mathrm{~cm}^{2} / \mathrm{s}$, and thus, the oxygen content of copper can be changed by annealing in controlled $\mathrm{p}_{2}$ environments. Yoshino [65] demonstrated that post-bonding anneals in low $\mathrm{p}_{2}$ environments degrade the peel strength or push strength, and that anneals in which $\mathrm{PO}_{2}$ is cycled from slightly above to slightly below that required for copper-cuprous oxide equilibrium lead to reproducible and reversible strength changes.

Role of Impurities and Interphases

Studies by Rogers et al. [71] and Rühle et al. [57] have shown that the levels of dissolved oxygen in even high-purity copper foils are sufficient to induce formation of interphases that impact the mechanical properties of copper/sapphire assemblies. In the work of Rogers et al. [71], cuprous oxide needles were present at the interface between $99.95 \%$ pure copper and sapphire after $24 \mathrm{~h} \mathrm{HV}$ diffusion bonding at $1040^{\circ} \mathrm{C}$ even though the ambient $p_{\mathrm{O}_{2}}$ during diffusion bonding $\left(\approx 3 \times 10^{-10} \mathrm{~atm}\right)$ was well below the copper-cuprous oxide equilibrium $p_{\mathrm{O}_{2}}\left(\approx 1.6 \times 10^{-6} \mathrm{~atm}\right)$. The copper foil was found to contain $\approx 1200$ atomic ppm (ppma) oxygen. Rühle et al. [57] bonded sapphire to "pure" copper foils and copper foils with 60 ppma dissolved oxygen $(\underline{\mathrm{O}})$ under uHV conditions ( 1 to $3 \mathrm{~h}, 1.5 \mathrm{MPa}$ bonding pressure, $900^{\circ} \mathrm{C}$ ). Although no interphases were detected when pure copper was used, bonds made with the foils containing 60 ppma $\underline{\mathrm{O}}$ yielded a reaction layer of either cuprous oxide or a copper aluminate $\left(\mathrm{CuAlO}_{2}\right)$ at the copper/sapphire interface. Fracture energy measurement comparisons show that bonds made with copper foils containing 60 ppma $\underline{O}$ yielded approximately four- to seven-fold higher $G_{c}$ values [57].

When bonding experiments were repeated using a graphite enclosure, interfaces free of cuprous oxide needles were obtained. 
Controlled $\mathrm{PO}_{2}$ anneals $\left(1000^{\circ} \mathrm{C}, 24 \mathrm{~h}\right)$ were used by Rogers et al. [71] to study interphase formation at copper/sapphire interfaces. Sapphire/copper/sapphire diffusion-bonded assemblies were annealed at a $\mathrm{PO}_{2}$ of $\approx 10^{-7}$ atm to reduce the cuprous oxide particles, and induce the formation of a copper aluminate at the interface. Subsequent anneals at a $p_{\mathrm{O}_{2}}$ of $\approx 5 \times 10^{-9}$ atm reduced both the cuprous oxide and copper aluminate. An anneal at a $p_{\mathrm{O}_{2}}$ of $\approx 10^{-7}$ atm reformed copper aluminate. Experiments suggest that nucleation and dissociation of $\mathrm{CuAlO}_{2}$ is sluggish. Subsequent studies by Reimanis et al. [72] examined the effect of such post-bonding anneals and interphases on the fracture resistance of bonds. Results suggest that when cuprous oxide is the only interphase at the interface, crack propagation is locally enhanced. In contrast, when $\mathrm{CuAlO}_{2}$ is the only interphase present, crack trapping occurs, and crack propagation is impeded. The fracture energy for interfaces containing $\mathrm{CuAlO}_{2}$ is $\approx 190 \mathrm{~J} / \mathrm{m}^{2}$, whereas that for crack initiation in interphase-free interfaces is $\approx 125 \mathrm{~J} / \mathrm{m}^{2}$.

\section{Wetting/Dewetting Studies}

Solid Copper on Alumina/Sapphire

The wetting behavior of liquid copper on sapphire has been discussed in a prior section; pure copper liquid does not wet sapphire. Several studies have focussed on the stability of thin solid copper films on sapphire $[73,74]$. The results indicate that thin films are morphologically stable to at least $430^{\circ} \mathrm{C}[74]$, but dewet and evolve into discrete copper clusters when annealed at $650^{\circ} \mathrm{C}$ at a $\mathrm{P}_{\mathrm{O}_{2}}$ consistent with copper-cuprous oxide equilibrium [73]. Measurements of contact angles of solid copper droplets on sapphire indicate the majority lie between $81-90^{\circ}$, and none are greater than $120^{\circ}[73]$.

\section{Copper-Niobium Alloys on Alumina}

Nakashima has studied the wetting of niobium-saturated copper on alumina and sapphire substrates at $1150^{\circ} \mathrm{C}[22]$. Niobium additions result in an immediate (short-term) decrease in the contact angle of liquid copper on polycrystalline alumina from $\approx 130^{\circ}$ (pure copper) to $\approx 114^{\circ}$. The contact angle continues to decrease with increasing time, reaching values of $\approx 15^{\circ}$ after $6 \mathrm{~h}$. 


\section{Copper on Niobium}

Three studies of the wetting of copper on niobium have been published, differing in temperature and time span investigated, niobium purity, and the extent to which the role of oxygen was assessed. The sessile drop measurements of DeLima et al. [75] used 99.9\% pure niobium single crystals and polycrystals, as well as polycrystalline niobium doped with 1.5 and 6.5 at\% oxygen, and $99.999 \%$ pure copper. Acute contact angles were obtained in all samples after $5 \mathrm{~min}$ at all temperatures from $1090^{\circ} \mathrm{C}\left(38-85^{\circ}\right)$ to $1300^{\circ} \mathrm{C}$ $\left(0-59^{\circ}\right)$ with the highest values corresponding to niobium doped with 6.5 at\% oxygen, and the lowest values for material processed in $\mathrm{H}_{2}: 10$ vol ppm $\mathrm{H}_{2} \mathrm{O}$ atmosphere. At fixed temperature and atmosphere, (100) and (110) single crystals and polycrystalline samples showed distinct wetting behaviors. Hodkin et al. [51] measured contact angles and dihedral angles for spectroscopically pure copper on two different $\approx 99.7 \%$ pure niobium polycrystalline substrates at $1500^{\circ} \mathrm{C}$. The reported contact angle for copper on niobium after $120 \mathrm{~h}$ is $<3^{\circ}$, and is consistent with the general data trend in this system towards lower contact angles with increasing temperature. Sessile drop measurements by Nakashima [22] evaluated the wetting of $99.999 \%$ pure copper on $99.99 \%$ pure niobium foil at $1150^{\circ} \mathrm{C}$ in vacuum. The results indicated an initial contact angle of $67^{\circ}$, which decreased to $\approx 40^{\circ}$ in $5-10$ min, and decreased more slowly to $\approx 28^{\circ}$ after $4 \mathrm{~h}$ at $1150^{\circ} \mathrm{C}$. The initial contact angle values are similar to those reported by DeLima et al. [75]; the long-time contact angle is significantly lower. Collectively, the results indicate that contact angles are acute, and decrease with decreasing oxygen content in niobium, $\boldsymbol{\nabla}$ increasing temperature, and increasing time at temperature.

\section{Experimental Procedure}

Joints were produced by coating alumina with a relatively thin copper layer, inserting a thicker niobium foil between the coated surfaces, and processing the resulting sandwich/assembly in a vacuum hot press at $\approx 1150^{\circ} \mathrm{C}$ or $\approx 1400^{\circ} \mathrm{C}$ with an applied pressure of $\approx 2 \mathrm{MPa}$. Each joined assembly was machined into beams for fracture strength testing. Further characterization of the joints was performed to relate

\footnotetext{
$\boldsymbol{\nabla}$ Unpublished work by Saiz et al. [76] has examined the effect of oxygen additions to copper on the wetting behavior. Contact angles near $80^{\circ}$ are obtained when $99.999 \%$ pure copper is placed on $99.9 \%$ pure niobium at $1150^{\circ} \mathrm{C}$ in gettered argon. If "electronic grade" copper (which contains oxygen) is used instead, then contact angles $<20^{\circ}$ are obtained. If electronic grade copper is annealed in $\mathrm{H}_{2}$ prior to the wetting experiment, contact angles close to $60-70^{\circ}$ are obtained.
} 
microstructure and processing conditions to the observed strengths. Post-bonding anneals were conducted to explore the effects of temperature and environment on joint stability. Many of the materials and experimental procedures used in this work duplicate those used previously [20,77].

\section{Materials}

The majority of joints fabricated used a $99.5 \%$ pure, $\geq 98 \%$ dense alumina (Coors TeCHNICAL Ceramics Co., Oak Ridge, TN) in the form of $19.5 \mathrm{~mm} \times 19.5 \mathrm{~mm} \times 22.5 \mathrm{~mm}$ blocks. Bonding surfaces were ground flat using a surface grinder, then lapped with progressively finer size $(9,6,3,1 \mu \mathrm{m})$ diamond suspensions (South Bay Technologies, San Clemente, ca), and finished by polishing with a colloidal silica suspension (Struers, Westlake, $\mathrm{OH}$ ). Some joints were also fabricated using $\approx 0.5 \mathrm{~mm}$ thick, highpurity, optical finish, $c$-axis $\left( \pm \approx 1^{\circ}\right)$ sapphire substrates (Meller Optics Inc., Providence, RI) that required no additional polishing.

Pieces of foil, $20 \mathrm{~mm} \times 23 \mathrm{~mm}$, were cut from a larger sheet of $127 \mu \mathrm{m}$ thick high-purity $(99.99 \%$ pure) niobium foil (Goodfellow, Berwyn, pa). The cut foil was pressed and flattened between two steel gauge plates. Afterwards, the foil was washed in a water-detergent mix, given an ultrasonic cleaning in isopropyl alcohol for at least $15 \mathrm{~min}$, rinsed successively in ethanol and nanopure water (minimum $18 \mathrm{M} \Omega+\mathrm{cm}$ resistivity) and then dried with warm air. A commercial copper wire (Consolidated Companies Wire and Associated, Chicago, il) used in prior studies served as the copper source.

\section{Coating Procedure}

Copper was deposited onto the polished and cleaned alumina substrates by evaporation in a high vacuum chamber. Copper wire pieces were cleaned ultrasonically in isopropyl alcohol for at least 15 min, rinsed in distilled water and bright dipped in a 5:1 nitric acid:water solution for 5-10 s to remove surface oxide. After bright dipping, the copper was immediately rinsed in distilled water and left submerged in isopropyl alcohol. Just prior to loading the deposition system, the copper pieces were rinsed in nanopure water and blown dry with air. Cleaned copper pieces were placed into tungsten wire baskets, and the deposition chamber was then evacuated to $<2.5 \times 10^{-9}$ atm before heating began. During coating, the

chamber pressure ranged from $3 \times 10^{-8}$ to $3 \times 10^{-7}$ atm; after coating, the pressure quickly dropped below 
$2.5 \times 10^{-9} \mathrm{~atm}$. The copper-coated substrates were left in the vacuum deposition chamber until the niobium core layer was cleaned and ready for sample assembly. Film thickness measurements were performed on glass cover slips placed into the chamber during deposition using both step height (profilometry) and weight gain measurements as described previously [20]. The film thickness varies somewhat from sample to sample and with position on a substrate surface. The average thickness is $\approx 3 \mu \mathrm{m}$.

\section{Bonding Conditions and Hot Press}

Cleaned niobium foils were placed between copper-coated alumina or sapphire substrates, and loaded into a vacuum hot press. Joints in this study were prepared in a hot press equipped with graphite heating elements, shields, and furniture, that reaches temperatures $>1600^{\circ} \mathrm{C}$. Prior joining work [20] used a hot press with molybdenum heating elements and shields and alumina furniture; this hot press only reaches $\approx 1200^{\circ} \mathrm{C}$. The temperature was increased at $4^{\circ} \mathrm{C} / \mathrm{min}$, however, occasionally the heating cycle had to be interrupted in order to maintain the vacuum below $1.3 \times 10^{-7}$ atm. Joints were processed at $\approx 1150^{\circ} \mathrm{C}$ or $\approx 1400^{\circ} \mathrm{C}$ for $6 \mathrm{~h}$ under high vacuum with the applied pressure set at the minimum values possible in the two hot presses. Pressures were applied at the onset of heating and maintained. Samples were cooled at $2^{\circ} \mathrm{C} / \mathrm{min}$. More detailed information is summarized in TABLE I.

\section{Beam Preparation}

The as-processed blocks were machined into rectangular beams, $\approx 3 \mathrm{~mm} \times \approx 3 \mathrm{~mm}$ in cross section and $\approx 4 \mathrm{~cm}$ in length, with the metal interlayer at the beam center. The joined block assembly was first cut into plates, one face of which was ground flat and polished, generally to a $1 \mu \mathrm{m}$ finish; details are available elsewhere [77]. The polished plates were subsequently cut into beams. The tensile edges of flexure beams were beveled on a $6 \mu \mathrm{m}$ grinding plate to remove machining flaws that could initiate failure. Subsequently, beams were successively cleaned with acetone, soap and water, and isopropyl alcohol. Just prior to mechanical testing, the beams were cleaned ultrasonically in a denatured HPLC grade ethanol (ALDRICH Chemical Company Inc., Milwaukee, wi) and blown dry with warm air. This process primarily serves to remove water trapped in the pores of the ceramic.

\footnotetext{
The "graphite" hot press is expected to provide a lower oxygen partial pressure environment during bonding.
} 


\section{Post-bonding Heat Treatments}

In order to investigate the effect of prolonged anneals at elevated temperature and differing oxygen partial pressures on beam strength and microstructure, beams which had been beveled and cleaned were placed inside an alumina crucible, heated at $30^{\circ} \mathrm{C} / \mathrm{min}$ and annealed at $1000^{\circ} \mathrm{C}$ for various lengths of time. Anneals in gettered argon were performed in a furnace with molybdenum heating elements and shields; vacuum anneals were performed in a furnace with tungsten heating elements and molybdenum shields.

For the gettered argon anneals, the argon flows through two tube furnaces prior to entering the annealing furnace, The first is held at $\approx 40^{\circ} \mathrm{C}$ and contains anhydrous calcium sulfate (W. A. Hammond Drierite Co., Xenia, oH) which removes excess water vapor from the argon. The second tube furnace contains titanium and zirconium chips at $\approx 800^{\circ} \mathrm{C}$ which react with oxygen in the argon. Assuming that equilibrium is reached at $800^{\circ} \mathrm{C}$, a $p_{\mathrm{O}_{2}}$ of the order of $10^{-44} \mathrm{~atm}$ is predicted. This $\mathrm{PO}_{2}$ would be sufficient to reduce alumina, and thus, a higher $p_{\mathrm{O}_{2}}$ is expected to prevail during anneals at $1000^{\circ} \mathrm{C}$. If the $\mathrm{p}_{\mathrm{O}_{2}}$ is dictated by aluminum-alumina equilibrium, one expects a $p_{\mathrm{O}_{2}}$ of the order of $10^{-34} \mathrm{~atm}$. This $p_{\mathrm{O}_{2}}$ and the flow rates are sufficiently low that material losses even after anneals of $200 \mathrm{~h}$ duration would be immeasurably small.

During the high vacuum anneals, the total pressure was typically $<7 \times 10^{-8}$ atm during heating and fell below $10^{-8} \mathrm{~atm}$ after a short time at the annealing temperature. For longer anneals, the total pressure was in the $10^{-10} \mathrm{~atm}$ range for much of the duration. At $1000^{\circ} \mathrm{C}$, the equilibrium oxygen partial pressure for tungsten-tugnsten oxide and molybdenum-molybdenum oxide equilibrium are comparable ( $\left.\approx 10^{-15} \mathrm{~atm}\right)$. This pressure would be sufficiently low to reduce cuprous oxide and copper aluminate, but exceeds the equilibrium $\mathrm{P}_{\mathrm{O}_{2}}$ for niobium-niobium oxide equilibrium $\left(\approx 10^{-25}\right.$ atm at $\left.1000^{\circ} \mathrm{C}\right)$. Thus, some oxidation of niobium may occur during annealing to reduce the ambient $p_{\mathrm{O}_{2}}$.

Mechanical Testing

\section{Room Temperature}

Beams were tested at room temperature using four-point bending. The inner and outer spans were 9 and $25 \mathrm{~mm}$, respectively. Testing was done with a displacement rate of $50 \mu \mathrm{m} / \mathrm{min}$. Strengths were calculated from the load at failure using standard relationships derived for monolithic elastic materials, i.e., 
no correction for stress concentrations arising from modulus misfit $[78,79]$ was attempted. Prior work had determined that under identical testing conditions, the average four-point bend strength of (unbonded and unannealed) alumina beams prepared from the same source material using similar cutting and polishing procedures is $\approx 280 \mathrm{MPa}[18]$.

High Temperature

For high-temperature bend tests, beams were loaded into a graphite testing jig situated between a graphite ram assembly in a tungsten heating element furnace. Inner and outer spans were again 9 and 25 $\mathrm{mm}$, respectively. The furnace chamber was evacuated and backfilled with argon which flows during heating, mechanical testing, and cooling of the sample. Typically, samples were heated to (and cooled from) the test temperature at $10^{\circ} \mathrm{C} / \mathrm{min}$, and held for at least $15 \mathrm{~min}$ at the test temperature prior to load application to thermally equilibrate the sample. Rams were displaced at $60 \mu \mathrm{m} / \mathrm{min}$ and the load versus displacement data was exported to a computer data acquisition system.

\section{Microstructural Characterization}

In prior work [20], bonds were fabricated at $1150^{\circ} \mathrm{C}$, and fracture proceeded primarily along one ceramic-metal interface. Fractographic analysis of such interfaces was reported previously [20]. The majority of the fractures in as-bonded samples prepared at $1400^{\circ} \mathrm{C}$ were ceramic failures. For selected samples in which failure was interfacial, beam fracture surfaces were mounted adjacent to one another so that equivalent fractographic locations were in mirror symmetry positions. The general microstructure at matching locations, the pore structure, and the fracture path could thus be readily identified. Fracture surfaces were first inspected using optical microscopy, and then examined using scanning electron microscopy (SEM).

For bonds prepared using sapphire substrates, the sapphire/interlayer interfacial microstructure was examined using optical microscopy. Samples were examined both in the as-processed state and after prolonged periods of post-bonding anneal. The evolution of microstructure at specific locations along the interface could be assessed by comparing images taken before and after annealing. 


\section{Results AND Discussion}

\section{Effect of Processing Conditions on Room-Temperature Mechanical Properties}

Prior room-temperature strength measurements [20] for alumina joined with a bonding pressure of $\approx 5.1 \mathrm{MPa}$ at $1150^{\circ} \mathrm{C}$ in a molybdenum element hot press are summarized and compared to the strength characteristics of the unbonded reference alumina in Figure 1. The average flexure strengths of these asbonded samples was $\approx 180 \mathrm{MPa}$ with a standard deviation of $\approx 25 \mathrm{MPa}$, and provides a basis for comparison.

The joint strengths obtained for a sample bonded at $1150^{\circ} \mathrm{C}$ in a graphite element hot press and a more modest bonding pressure of 2.2 $\mathrm{MPa}$ are shown in Figure 1. It is clear that the average strength has decreased $(80 \mathrm{MPa})$. All beams that survived the sample preparation procedures suffered interfacial failure. In addition, three of six plates failed during machining/handling of the bonded block, suggesting that the strength variation is even more severe than indicated. Either the reduced $p_{\mathrm{O}_{2}}$ or the reduced bonding pressure, or the combination of both results in substantial strength degradation.

Increasing the bonding temperature to $1400^{\circ} \mathrm{C}$, while maintaining the applied load (2.2 $\left.\mathrm{MPa}\right)$ and other parameters, improves the bond properties dramatically. In all three bonds prepared using these conditions, reproducibly high strengths were obtained. The strength results appear as one data set in Figure 1; the average strength is $240 \mathrm{MPa}$ with a standard deviation of $20 \mathrm{MPa}$. In room temperature bend tests, 25 samples failed entirely in the ceramic, failure in 6 initiated in the ceramic, and the remaining 11 failed along the interface. This suggests that there is a substantial change in the nature of the alumina/interlayer microstructure or adhesion, or both, as a result of the increase in bonding temperature. Copper segregation to the alumina/niobium interface is expected, but does not appear to have a strong adverse effect.

When the fracture surfaces of polycrystalline alumina samples bonded at $1150^{\circ} \mathrm{C}$ in molybdenum and graphite hot presses are compared, good ceramic-metal contact is indicated in both. There are few obvious interfacial flaws (unbonded regions), and the imprint of the ceramic microstructure is evident on the metal side of failed beams. Thus, the degree of ceramic-metal contact does not appear to cause the 
strength difference. What is apparent is that the samples processed in graphite have a significantly higher area fraction of copper, and thus, copper/alumina contact along the interface.

To examine whether this was due to the difference in bonding pressure or to the difference in the ambient $\mathrm{PO}_{2}$, sapphire-based bonds were prepared in the graphite hot press at $1150^{\circ} \mathrm{C}$ using bonding pressures of 1.6 and 5.0 MPa. Optical microscopy was used to examine the interface microstructure. In both samples regions were evident in which the copper film remained continuous, and regions could be found in which the film had broken up. A qualitative assessment suggests that the increase in bonding pressure leads to somewhat more breakup of the film, however, the difference is not dramatic. Moreover, the microstructure is quite inhomogeneous. It is possible that microstructural features at an interface with polycrystalline alumina have an important effect on the evolution. Bonds using polycrystalline alumina blocks are being prepared using a 5.0 MPa bonding pressure to see whether fracture strengths and fracture surface microstructures are then more similar to those observed in the original bonds prepared in the molybdenum hot press. It is possible that the greater area fraction of copper/sapphire interfaces, rapid diffusion of oxygen through a continuous copper liquid film, and a low ambient $p_{\mathrm{O}_{2}}$ combine to produce low strengths in joints prepared using low bonding pressures in a graphite hot press.

Several factors could in principle contribute to the substantial improvement in joint properties that accompanies an increase of the bonding temperature to $1400^{\circ} \mathrm{C}$. Temperature-induced changes in the alumina/interlayer microstructure could in principle be the result of changes in the amount of liquid formed, and its wetting behavior, or in the kinetics of morphological evolution.

Increasing the amount of liquid could facilitate the filling of interfacial voids. The copper-niobium phase diagram $[50]$ is a simple eutectic $\left(T_{\text {eut }} \approx 1080^{\circ} \mathrm{C}\right)$, and the liquidus is nearly vertical up to $\approx 1600^{\circ} \mathrm{C}$. At $1150^{\circ} \mathrm{C}$, the niobium-saturated liquid contains $\approx 0.7$ at $\%$ niobium while at $1400^{\circ} \mathrm{C}$ it contains $\approx 1.7$ at $\%$ niobium. As a result, the difference in the amount of liquid formed at $1150^{\circ} \mathrm{C}$ versus $1400^{\circ} \mathrm{C}$ is negligible.

\footnotetext{
$\diamond$ Although equilibration with a low ambient $\mathrm{p}_{2}$ could reduce the strength of copper/alumina interfaces, the equilibrium concentration of dissolved oxygen in copper is orders of magnitude lower than that in niobium at constant oxygen potential. Thus, under most conditions niobium would "getter" oxygen from copper. Diffusion of oxygen into niobium involves a much shorter diffusion distance $(\approx 65 \mu \mathrm{m})$ than diffusion of oxygen to the external surface (up to $\approx 1 \mathrm{~cm}$ ).
} 
To fill interfacial voids and redistribute the niobium-saturated copper liquid film, it is necessary for $\left(\theta_{1}+\theta_{2}\right) \leq 180^{\circ}$, where $\theta_{1}$ and $\theta_{2}$ are the contact angles for the liquid on the ceramic and metal, respectively. Prior work has demonstrated that for copper-niobium liquids on alumina, $\theta_{1} \leq 114^{\circ}$ after short times, and decreases with increasing time [22]. Even the short-term value for $\theta_{1}$, requires only that $\theta_{2} \leq 66^{\circ}$ to satisfy $\left(\theta_{1}+\theta_{2}\right) \leq 180^{\circ}$. Contact angle measurements [75] suggest that $\theta_{2} \leq 66^{\circ}$ for copper-niobium at $1150^{\circ} \mathrm{C}$ unless the niobium contains $>1.5$ at $\%$ oxygen and $\theta_{2}>64^{\circ}$. However, there is no reason to expect such high oxygen levels in the present experiments; the wetting studies of Nakashima [22] and the present joining studies used niobium foil from the same source and lot. Since $\theta_{2}$ in the copper-niobium system decreases significantly with increasing temperature and time, the condition $\left(\theta_{1}+\theta_{2}\right)<180^{\circ}$ would certainly be met at $1400^{\circ} \mathrm{C}$, and a greater driving force for liquid redistribution would be expected. Although more rapid redistribution would be desirable in PTLP bonding where isothermal solidification can occur, this is not an issue in the present system. Moreover, since good ceramic-metal contact and few interfacial defects were evident in samples prepared at $1150^{\circ} \mathrm{C}$ in graphite, it seems unlikely that the significant improvement in the strength of joints prepared at $1400^{\circ} \mathrm{C}$ is due purely to improved wetting.

Fracture surfaces of the (few and generally weaker) beams that failed along the interface and studies of interfacial microstructures in sapphire-based bonds prepared at $1400^{\circ} \mathrm{C}$ (to be discussed shortly) indicate that at the higher temperature, breakup of the copper film into discrete particles occurs more rapidly than at $1150^{\circ} \mathrm{C}$. Although the interfacial microstructures are similar to those obtained at lower temperature and higher bonding pressure in a molybdenum hot press [20], the joint properties are not. The increased temperature results in a clear improvement in properties, the underlying cause of which is not yet fully understood.

INTERFACIAL MICROSTRUCTURE EVOLUTION

Samples bonded at $1150^{\circ} \mathrm{C}$ in a molybdenum-element hot press failed primarily along the interface, and this permitted examination of the ceramic/interlayer interface structure. Extensive redistribution of the copper-rich liquid, and the formation of isolated particles of copper along the interface were evident [20]. In 
the current study, two bonds were prepared at $1400^{\circ} \mathrm{C}$ using c-axis sapphire so that the nature of the interface microstructure could be assessed.

Figure 2 shows a series of optical micrographs taken at different locations along the interface of an as-processed joint. The micrographs suggest a sequence of evolution in which niobium/sapphire contact is first achieved along the niobium grain boundaries, Figure $2 a$, somewhat reminiscent of the findings of Reimanis [52]. In the present case, this is most likely due to the formation of grain boundary grooves as the copper dissolves niobium and "etches" the grain boundary, and the formation of flanking grain boundary groove ridges. De Lima et al. [75] provide evidence of preferential (diffusional) penetration of copper along niobium grain boundaries, and report that the major dissolution of the niobium also occurred along the grain boundary. The grain boundary ridges will contact the sapphire, and localized liquid-phase assisted growth of a niobium/sapphire contact zone ensues. When the niobium/sapphire contact area is small, and the bonding load is amplified, deformation of the niobium may contribute to contact growth. One can anticipate that transport of niobium within the niobium-saturated copper liquid will be rapid. When ridgesapphire contact is complete around the perimeter of a given grain, a thin layer of niobium-saturated copper liquid is isolated atop the grain. Growth of the contact zone leads to regression of this liquid layer towards the grain center. Consistent with observations by Hodkin et al. [51], the copper/ niobium interface is not facetted, and thus, the morphology differs from that observed during pore removal [52]. Capillary instabilities reminiscent of those in high-temperature crack healing and in the breakup of thin (solid) metal films on ceramic substrates occur along the edges of the liquid, resulting in the formation of "cylindrical" ligaments of copper-rich liquid along the interface, Figure $2 \mathrm{~b}$. These ligaments subsequently appear to undergo Rayleigh instabilities, resulting in the formation of isolated copper droplets at the interface, as shown in Figure 2c.

Neither the substrate nor the foil are perfectly flat. Although the deviations from planarity may be small in an absolute sense, contact between these nonplanar surfaces will create local points of contact and thereby potentially substantial variations in the liquid film thickness. Spatial variations in the liquid film thickness, in tandem with the polycrystalline nature of the niobium foil are believed to contribute to the substantial spatial variability in the microstructure. The grain boundary misorientation varies from grain- 
to-grain, causing a spatial variation in the grain boundary groove angle and grooving kinetics. Variations in the liquid film thickness can induce variations in the ridge height that must be achieved to initiate niobiumsapphire contact. Unless the foil is strongly textured, each exposed niobium grain surface will have a different orientation and this will cause grain-to-grain variations in $\theta_{2}$. As a result, it is not surprising that substantial variations in the microstructure are evident. When polycrystalline alumina substrates are used instead of sapphire, defects in the ceramic surface, grain-to-grain variations in the alumina surface orientation and alumina grain boundary groove characteristics can all be important, and may reduce the spatial scale of variability in microstructural evolution.

\section{High temperature Strength and Failure mode}

The microstructural observations on sapphire/interlayer couples suggest that over a substantial fraction of the sapphire/interlayer interface, niobium is in contact with sapphire. The room-temperature fracture results for samples bonded at $1400^{\circ} \mathrm{C}$ show highly reproducible strengths. As a result, a limited number of beams from samples bonded at $1400^{\circ} \mathrm{C}$ were subjected to short-time elevated temperature bend tests in an argon atmosphere.

The test results are summarized in Figure 3. Five beams from this sample were tested at room temperature. Four failed in the ceramic; in a fifth, failure initiated within the ceramic, but the crack was drawn to the interface. The average room temperature strength from this subset was of the order $245 \mathrm{MPa}$, consistent with the larger set of data from bonds prepared at $1400^{\circ} \mathrm{C}$. Average strengths $>200 \mathrm{MPa}$ are retained to temperatures of $900^{\circ} \mathrm{C}$, with the lowest strengths corresponding to interfacial failures, and at $1100^{\circ} \mathrm{C}$, a bend strength of $\approx 85 \mathrm{MPa}$ is observed. Even allowing for a $\pm 20^{\circ} \mathrm{C}$ error in the temperature measurement, this test temperature is above $99 \%$ of the melting point of copper. This observation does suggest that substantial niobium/alumina bonding is achieved, and argues against the existence of a very thin residual copper layer along the interface. Perhaps most striking about the results is that many of the failures (see insert in Figure 3) occur within the ceramic and thus, the observed strength decrease appears to reflect the characteristics of the alumina, not of the joint itself. (Presumably, the strength decrease is the result of a small amount of glassy phase in this alumina.) 


\section{EFFECT OF POST-BONDING HEAT TREATMENTS ON ROOM TEMPERATURE STRENGTH}

The potentially important effect of the ambient oxygen partial pressure on near-interfacial chemistry in niobium/alumina(sapphire) bonds has been discussed in numerous publications [e.g., 29-31, $38,39,42,46,47,80,81]$. The high-temperature mechanical tests may be of too short a duration for any substantial adjustment of the interface chemistry to occur over a spatial scale that would affect failure. In a prior study [20], bonds fabricated at $1150^{\circ} \mathrm{C}$ in a molybdenum hot press were subjected to $10 \mathrm{~h}$ anneals at $1000^{\circ} \mathrm{C}$ in gettered argon, and retested at room temperature. The results suggested a possible improvement in strength, however, due to other factors, a definitive conclusion was not possible. In subsequent experiments, samples processed at $1400^{\circ} \mathrm{C}$ were subjected to $5 \mathrm{~h}$ and $50 \mathrm{~h}$ gettered argon anneals at $1000^{\circ} \mathrm{C}$, and retested at room temperature. Although a $5 \mathrm{~h}$ anneal had no discernable effect, there appeared to be a strength drop after a $50 \mathrm{~h}$ anneal. A more complete investigation of this behavior was pursued, both to explore potential effects of prolonged high temperature exposure on strength, and to see whether any evidence could be obtained for an effect of oxygen partial pressure on strength characteristics.

Figure 4 summarizes the results of room temperature strength tests after beams processed at $1400^{\circ} \mathrm{C}$ were annealed for periods of $0,5,50,200$, and $220 \mathrm{~h}$ at $1000^{\circ} \mathrm{C}$ in gettered argon. Beams tested in the as-processed state had an average fracture strength of $240 \mathrm{MPa}$, and ceramic failures outnumber interfacial failures by a roughly $3: 1$ ratio. A single sample annealed for $5 \mathrm{~h}$ failed in the ceramic at a stress of $\approx 240 \mathrm{MPa}$. An increase in the anneal time to $50 \mathrm{~h}$ results in a decrease in the mean strength to $\approx 210 \mathrm{MPa}$, with ceramic and interfacial failures still in a 3:1 ratio. When anneal times are increased to 200 or $220 \mathrm{~h}$, the mean strength is again somewhat less than that of as-processed samples. Although a least squares fit of the strength data does suggest a decline in strength with increasing anneal time, the decrease is modest. What is perhaps more significant is that all failures in this set occurred along the interface. The likelihood that all five samples annealed for $\geq 200 \mathrm{~h}$ would fail along the interface in the absence of some microstructural or microchemical change seems remote.

To explore whether the observed changes in fracture strength were the result of a microstructural or microchemical change that was purely the result of prolonged annealing, bend beams were also annealed for $200 \mathrm{~h}$ at $1000^{\circ} \mathrm{C}$ in a vacuum environment. Four beams failed at an average strength of $225 \mathrm{MPa}$, and 
three of four beams failed in the ceramic, as shown in Figure 4. Sapphire couples were also annealed for 200 $h$, and the microstructures of the same areas at the interface compared. As shown in Figure 5, there is no discernable change in the interfacial microstructure; this also supports the view that the extensive microstructural adjustments that occur during bonding are facilitated by niobium diffusion within the copper-rich liquid. Such prolonged anneals should also allow for copper dissolved in the near-interfacial region to segregate to the interface. There is no substantial strength loss and no obvious shift in fracture path when samples are annealed in vacuum.

In an effort to understand the different fracture path tendencies, the fracture surfaces of (the one) vacuum annealed and the argon annealed beams that failed along the interface were compared. In Figure 6, four micrographs are presented. The left-hand column shows the ceramic (top) and metal (bottom) side of the fracture surface of a vacuum-annealed sample. The tensile edge of the beam lies at the common edge of the micrographs, and thus equivalent positions are situated at equivalent distances from the common edge. One notes that the ceramic grain structure, clearly evident in the top micrograph, is "reflected" across this edge, implying good ceramic-metal contact, and that grain boundary grooves formed in the alumina cause corresponding features, presumably ridges, on the niobium surface. The failure proceeds through the copper, leaving traces on both sides of the fracture surface. In contrast, the argon-annealed samples show that a microstructurally distinct "reaction product" has formed near the tensile surface, and fracture appears to proceed through this layer. By scanning the tensile edge and adjusting the focus, one concludes that this reaction product lies (or at least extends) on the interlayer side of the original interlayer/alumina interface. The thinness and limited spatial extent of this layer have complicated efforts to determine its nature. EDS measurements indicate the layer contains niobium and aluminum. Since similar results are obtained on the metal fracture surface, one can preclude that the aluminum signal comes from the underlying alumina. Beyond this region, there again appears to be intimate contact between the ceramic and metal as evidenced by the imprint of the alumina grain boundaries on the niobium. Since anneals in very low $p_{\mathrm{O}_{2}}$ environments would deplete the niobium of oxygen and thereby allow higher aluminum concentrations to be reached, the possibility exists that the reaction product is a niobium aluminide $\left(\mathrm{Nb}_{3} \mathrm{Al}\right)$. The formation 
of a particularly brittle intermetallic interphase may facilitate failure initiation along the interface and contribute to the observed change in fracture path. Further tests are in progress.

\section{Summary and Conclusions}

The results suggest that processing temperature, bonding pressure and the furnace environment (ambient oxygen partial pressure) can play a key role in defining the strength characteristics of a joined assembly. Polycrystalline aluminas joined using copper/niobium/copper interlayers at $1150^{\circ} \mathrm{C}$ and $1400^{\circ} \mathrm{C}$ in a graphite element hot press have dramatically different properties. Similarly, joints prepared at two different bonding pressures at $1150^{\circ} \mathrm{C}$ exhibit different interfacial microstructures. Although intimate ceramic-metal contact is achieved in both $1150^{\circ} \mathrm{C}$ bonds, a clear difference in the failure behavior exists. Fracture surfaces of alumina beams and interfacial microstructures in sapphire-based bonds seem to suggest that the strengths increase as the area fraction of niobium/alumina (versus copper/alumina) contact at the interface increases. An increase in the bonding temperature at constant pressure, and to a much lesser degree an increase in pressure at constant bonding temperature appear to lead to more complete "dewetting" of the copper films and more extensive formation of niobium/sapphire contact. Whether the relatively lower $\mathrm{PO}_{2}$ expected in a graphite environment also detrimentally affects the joint properties remains to be confirmed. The joints produced in a graphite hot press at $1400^{\circ} \mathrm{C}$ are formed at low ambient $\mathrm{P}_{\mathrm{O}_{2}}$, however, they exhibit consistently good room temperature properties.

Additional experiments using sapphire are being conducted to allow a more thorough and quantitative comparison of the interfacial microstructures produced in the two furnace environments at $1150^{\circ} \mathrm{C}$, and those produced in graphite at $1150^{\circ} \mathrm{C}$ and $1400^{\circ} \mathrm{C}$. In addition, polycrystalline alumina assemblies are being fabricated in the graphite hot press at $1150^{\circ} \mathrm{C}$ with a higher joining pressure and will be tested to isolate the effect of bonding pressure on fracture characteristics.

The high fraction of ceramic failures in "optimized" joints implies that further improvements in strength, and perhaps an even higher frequency of ceramic failure could be achieved with an alumina of 
higher strength and an improved microstructure. Preliminary room-temperature strength results on bonds produced using a higher-strength higher-purity commercial alumina support this contention [82].

The observation that reasonable strengths could be maintained to temperatures beyond those accessible with conventional brazes (e.g., CUSIL $\mathrm{ABA}^{\mathrm{rm}}$ ) is encouraging. It suggests that the use of multilayer interlayers in which thin liquid-forming layers undergo similar morphological changes may provide a new means of producing joints that are useful at elevated temperatures. Since the phase diagram and kinetic considerations in selecting such liquid formers differ from those for PTLP bonding, this may provide additional options for interlayer design. Since high-temperature strengths were often limited by the properties of the ceramic it may be possible to further improve the strength-temperature characteristics of such joints, and to extend the utility of the joint to higher temperatures than presently demonstrated.

Finally, the results indicate that prolonged high-temperature anneals in a low $p_{\mathrm{O}_{2}}$ ambient can have an adverse effect on joint performance. Both the vacuum and gettered argon anneals involve $p_{\mathrm{O}_{2}}$ values well below those required to oxidize copper or to form copper aluminates, and as a result, copperbased interphases are not expected to play a role in the present studies. As would be expected on thermodynamic grounds, interphases were not evident in as-bonded sapphire couples even in regions of extensive sapphire/copper contact. Although anneals in vacuum produce no obvious microstructural changes, anneals in gettered argon produce what appears to be a reaction layer or interphase along the ceramic/interlayer interface near the external surface. The nature of this reaction layer needs to be identified. One can speculate that if the thin reaction layer is mechanically weak it may provide a preferred site for failure initiation, and that once initiated near the ceramic/interlayer interface failure simply proceeds along the ceramic/interlayer interface. An alternative explanation is that prolonged exposure to a low $\mathrm{PO}_{2}$ environment induces a more extensive change in the ceramic/interlayer chemistry that affects the adhesion and thereby the fracture path. Further work will be required to resolve this issue. 


\section{Acknowledgements}

This research was supported by the Director, the Office of Energy Research, Office of Basic Energy Sciences, Materials Sciences Division of the U.S. Department of Energy under Contract No. DE-AC0376SF00098. The authors thanks Rowland Cannon, Ivar Reimanis, Eduardo Saiz, Mark Sixta and Tony Tomsia for helpful discussions, experimental assistance, and access to unpublished research results. 


\section{REFERENCES}

[1] M. G. Nicholas and D. A. Mortimer, Mater. Sci. Tech., 1, [9], 657-65 (1985).

[2] K. Suganuma, Y. Miyamoto, and M. Koizumi, Ann. Rev. Mater. Sci., 18, 47-33 (1988).

[3] R. E. Loenman and A. P. Tomsia, Am. Ceram. Soc. Bull., 67, [2], 375-80 (1988).

[4] G. Elssner and G. Petzow, ISIJ Int., 30, [12], 1011-1032 (1990).

[5] M. G. Nicholas, Joining of ceramics, 1st ed. London; New York: Published on behalf of the Institute of Ceramics by Chapman and Hall, 1990.

[6] R. E. Loemman, in Surfaces and interfaces in ceramic and ceramic-metal systems, J. A. Pask and A. G. Evans, Eds. New York: Plenum Press, 1981, pp. 701-711.

[7] R. D. Brittain, S. M. Johnson, R. H. Lamoreaux, and D. J. Rowcliffe, J. Am. Ceram. Soc., 67, [8], 522-6 (1984).

[8] M. L. Mecartney, R. Sinclair, and R. E. Loemman, J. Am. Ceram. Soc., 68, [9], $472-8$ (1985).

[9] S. M. Johnson and D. J. Rowcliffe, J. Am. Ceram. Soc., 68, [9], 468-72 (1985).

[10] S. Baik and R. Raj, J. Am. Ceram. Soc., 70, [5], C105-7 (1987).

[11] P. A. Walls and M. Ueki, J. Am. Ceram. Soc., 78, [4], 999-1005 (1995).

[12] M. Gopal, L. C. De Jonghe, and G. Thomas, Acta Mater., 46, [7], 2401-5 (1998).

[13] S. J. Glass, F. M. Mahoney, B. Quillan, J. P. Pollinger, and R. E. Loenman, Acta Mater., 46, [7], 2393-9 (1998).

[14] T. Iseki, K. Yamashita, and H. Suzuki, Proc. Brit. Ceram. Soc., 31, 1-8 (1981).

[15] T. Iseki, K. Yamashita, and H. Suzuki, J. Am. Ceram. Soc., 64, [1], C13-14 (1981).

[16] Y. Iino and N. Taguchi, J. Mater. Sci. Lett., 7, [9], 981-2 (1988).

[17] Y. Inno, J. Mater. Sci. Lett., 10, [2], 104-6 (1991).

[18] M. L. Shalz, B. J. Dalgleish, A. P. Tomsia, and A. M. Glaeser, J. Mater. Sci., 28, [6], 1673-84 (1993).

[19] M. L. Shalz, B. J. Dalgleish, A. P. Tomsia, and A. M. Glaeser, J. Mater. Sci., 29, [12], 3200-8 (1994).

[20] M. L. Shalz, B. J. Dalgleish, A. P. Tomsia, R. M. Cannon, and A. M. Glaeser, J. Mater. Sci., 29, [14], 3678-90 (1994).

[21] B. J. Dalgleish, A. P. Tomsia, K. Nakashima, M. R. Locatelli, and A. M. Glaeser, Scripta Metall. Mater., 31, [8], 1043-8 (1994).

[22] M. R. Locatelli, A. P. Tomsia, K. Nakashima, B. J. Dalgleish, and A. M. Glaeser, Key Eng. Mater., 111-112, 157-90 (1995).

[23] B. J. Dalgleish, K. Nakashima, M. R. Locatelli, A. P. Tomsia, and A. M. Glaeser, Ceram. Int., 23, [4], 313-22 (1997).

[24] G. Ceccone, M. G. Nicholas, S. D. Peteves, A. P. Tomsia, B. J. Dalgleish, and A. M. Glaeser, Acta Mater., 44, [2], 657-67 (1996).

[25] M. Paulasto, G. Ceccone, and S. D. Peteves, Scripta Mater., 36, [10], 1167-73 (1997).

[26] S. D. Peteves, M. Paulasto, G. Ceccone, and V. Stamos, Acta Mater., 46, [7], 2407-14 (1998).

[27] S. Morozumi, M. Kikuchi, and T. Nishino, J. Mater. Sci., 16, [8], 2137-44 (1981).

[28] M. Rühle, K. Burger, and W. Mader, J. Microsc. Spectrosc. Electron. (France), 11, $163-77$ (1986).

[29] G. Elssner and G. Petzow, Z. Metallkde., 64, [4], 280-86 (1973). 
[30] M. Rühle, M. Backhaus-Ricoult, K. Burger, and W. Mader, in Ceramic Microstructures '86, J. A. Pask and A. G. Evans, Eds. New York: Plenum Press, 1987, pp. 295305.

[31] K. Burger, W. Mader, and M. Rühle, Ultramicroscopy, 22, 1-13 (1987).

[32] H. F. Fischmeister, W. Mader, B. Gibbesch, and G. Elssner, in Interfacial structure, properties, and design, vol. 122, Mat. Res. Soc. Proc., W. A. T. Clark, C. L. Briant, and M. H. Yoo, Eds. Pittsburgh, Pa.: Materials Research Society, 1988, pp. 529-540.

[33] B. Gibbesch and G. Elssner, Acta Metall. Mater., 40, [Supplement], S59-66 (1992).

[34] B. Gibbesch, G. Elssner, W. Mader, and H. Fischmeister, Ceram. Eng. Sci. Proc., 10, [11-12], 1503-14 (1989).

[35] D. Korn, G. Elssner, H. F. Fischmeister, and M. Rühle, Acta Metall. Mater., 40, [Supplement], S355-60 (1992).

[36] B. Gibbesch, G. Elssner, W. Mader, and H. F. Fischmeister, in Joining ceramics, glass, and metal, W. Kraft and Deutsche Gesellschaft für Metallkunde, Eds. Oberursel: DGM Informationsgesellschaft, 1989, pp. 65-72.

[37] M. Turwitt, G. Elssner, and G. Petzow, J. de Physique, 46, [Supplement C4], $123-7$ (1985).

[38] K. Burger and M. Rühle, Ceram. Eng. Sci. Proc., 10, [11-12], 1549-1566 (1989).

[39] K. Burger and M. Rühle, Ultramicroscopy, 29, [1-4], 88-97 (1989).

[40] G. Elssner, H. Jehn, and E. Fromm, High Temp.-High Press., 10, [5], 487-92 (1978).

[41] G. Elssner and G. Hörz, Z. Metallkde., 62, [3], 217-22 (1971).

[42] G. Elssner, S. Riedel, and R. Pabst, Prakt. Metall., 12, 234-43 (1975).

[43] R. A. Perkins and R. A. Padgett, Jr., Acta Metall., 25, [10], 1221-30 (1977).

[44] R. Kirchineim, Acta Metall., 27, [5], 869-78 (1979).

[45] G. I. Nikolaev and N. V. Bodrov, Russ. J. Phys. Chem., 52, [6], 821-823 (1978).

[46] M. Backhaus-Ricoult, Ber. Bunsenges. Phys. Chem., 90, [8], 684-90 (1986).

[47] J. T. Klomp, in Ceramic Microstructures '86, J. A. Pask and A. G. Evans, Eds. New York: Plenum Press, 1987, pp. 307-317.

[48] G. Elssner, D. Korn, and M. Rühle, Scripta Metall. Mater., 31, [8], 1037-42 (1994).

[49] S. Gerardi, in Metals Handbook, vol. 2, 10th ed. Materials Park, OH: ASM International, 1990, pp. 565-571.

[50] T. B. Massalski, H. Okamoto, and ASM International, Binary alloy phase diagrams, 2nd ed. Materials Park, Ohio: ASM International, 1990.

[51] E. N. Hodkin, M. G. Nicholas, and D. M. Poole, J. Less-Common Metals, 20, [2], 93-103 (1970).

[52] I. E. Reimanis, Acta Metall. Mater., 40, [Supplement], S67-74 (1992).

[53] C. A. M. Mulder and J. T. Klomp, J. de Physique, 46, [Supplement C4], 111-16 (1985).

[54] R. M. Crispin and M. G. Nicholas, Ceram. Eng. Sci. Proc., 10, [11-12], 1575-81 (1989).

[55] C. Beraud, M. Courbiere, C. Esnouf, D. Juve, and D. Treheux, J. Mater. Sci., 24, [12], 4545 54 (1989).

[56] L. Esposito, A. Bellosi, S. Guicciardi, and G. De Portu, J. Mater. Sci., 33, [7], 1827-36 (1998).

[57] M. Rühle, A. Liedtke, U. Alber, R. Schweinfest, and G. Elssner, in Interfacial Science in Ceramic Joining, A. Bellosi, T. Kosmac, and A. P. Tomsia, Eds.: Kluwer Academic Publishers, Dordrecht, The Netherlands, 1998, pp. 3-14. 
[58] B. C. Allen and W. D. Kingery, Trans. Aime, 215, [2], 30-37 (1959).

[59] M. Nicholas, R. R. D. Forgan, and D. M. Poole, J. Mater. Sci., 3, [1], 9-14 (1968).

[60] A. C. D. Chaklader, A. M. Armstrong, and S. K. Misra, J. Am. Ceram. Soc., 51, [11], 630-3 (1968).

[61] T. E. O'Brien and A. C. D. Chaklader, J. Am. Ceram. Soc., 57, [8], 329-32 (1974).

[62] K. Nogi, K. Oishi, and K. Ogino, Mater. Trans., JIM, 30, [2], 137-45 (1989).

[63] P. Nikolopoulos, S. Agathopoulos, and A. Tsoga, J. Mater. Sci., 29, [16], 4393-8 (1994).

[64] V. Ghetta, J. Fouletier, and D. Chatain, Acta Mater., 44, [5], 1927-36 (1996).

[65] Y. Yoshino, J. Am. Ceram. Soc., 72, [8], 1322-7 (1989).

[66] S. T. Kim And C. H. Kim, J. Mater. Sci., 27, [8], 2061-6 (1992).

[67] C. E. Ransley, J. Inst. Metals (London), 65, [1], 147-172 (1939).

[68] R. L. Pastorek and R. A. Rapp, Trans. Aime, 245, [8], 1711-1720 (1969).

[69] A. V. Ramana Rao and V. B. Tare, Z. Metallkde., 63, [2], 70-3 (1972).

[70] J. Orszagh and E. Bouillon, Memoires Scientifiques de la Revue de Metallurgie, 70, [4], 319-25 (1973).

[71] K. A. Rogers, K. P. Trumble, B. J. Dalgleish, and I. E. Reimanis, J. Am. Ceram. Soc., 77, [8], 2036-42 (1994).

[72] I. E. Reimanis, K. P. Trumble, K. A. Rogers, and B. J. Dalgleish, J. Am. Ceram. Soc., 80, [2], 424-32 (1997).

[73] C. M. Kennefick and R. Raj, Acta Metall., 37, [11], 2947-52 (1989).

[74] Q. Guo and P. J. Moller, Surface Science, 244, [3], 228-36 (1991).

[75] O. F. De Lima, M. Krehl, and K. Schulze, J. Mater. Sci., 20, [7], 2464-70 (1985).

[76] E. Saiz, R. M. Cannon, and A. P. Tomsia, unpublished research, 1998.

[77] R. A. Marks, M.S. Thesis, Department of Materials Science and Mineral Engineering, University of California, Berkeley, (2000).

[78] B. J. Dalgleish, M. C. Lu, and A. G. Evans, Acta Metall., 36, [8], 2029-35 (1988).

[79] H. C. Cao, M. D. Thouless, and A. G. Evans, Acta Metall., 36, [8], 2037-46 (1988).

[80] D. Knauss and W. Mader, Ultramicroscopy, 37, [1-4], 247-62 (1991).

[81] W. Mader and M. Ruhle, Acta Metall., 37, [3], $853-66$ (1989).

[82] R. A. Marks, unpublished research, 1999. 


\section{TABLES}

Table I: $\quad$ Summary of Processing Conditions for Each Joint

\begin{tabular}{|c|c|c|c|c|}
\hline Substrate & Hot Press & $\begin{array}{c}\text { Joining } \\
\text { Temperature } \\
\left({ }^{\circ} \mathrm{C}\right)\end{array}$ & $\begin{array}{c}\text { Applied } \\
\text { Load } \\
(\mathrm{MPa})\end{array}$ & $\begin{array}{c}\text { Holds } \\
\left({ }^{\circ} \mathrm{C} \text {-min }\right)\end{array}$ \\
\hline Coors alumina & graphite & 1394 & 2.2 & none \\
\hline Coors alumina & graphite & 1150 & 2.2 & none \\
\hline Coors alumina & graphite & 1394 & 2.2 & $1199-30$ \\
\hline Coors alumina & graphite & 1394 & 2.2 & $1169-56$ \\
\hline $\begin{array}{c}(0001) \text { sapphire } \\
\text { window }\end{array}$ & graphite & 1394 & 2.9 & $\begin{array}{c}1108-96 \\
1218-139 \\
1329-111\end{array}$ \\
\hline $\begin{array}{c}\text { (0001) sapphire } \\
\text { window }\end{array}$ & graphite & 1382 & 2.2 & none \\
\hline
\end{tabular}




\section{Figure Captions:}

Figure $1 \quad$ Plot of failure probability versus beam fracture strength illustrating effect of processing conditions on joint characteristics. The alumina reference material was unbonded and not annealed prior to testing.

Figure 2 Illustration of interfacial microstructures in a sapphire/copper/niobium couple bonded at $1400^{\circ} \mathrm{C}$ showing possible sequence for microstructural evolution: a) initial niobium/sapphire contact along grain boundary ridges, b) regression and instability of isolated copper films, and c) regions of largely niobium/sapphire contact with small isolated copper droplets.

Figure 3 Plot of beam fracture strength versus temperature. Strengths are retained to high temperature, and instances of ceramic failure are observed in the $900^{\circ} \mathrm{C}-1100^{\circ} \mathrm{C}$ test temperature interval. The insert shows examples of some of the higher temperature fractures. Points characterized as interfacial failures correspond to samples in which the failure initiated and propagated entirely along the interface. Points characterized as ceramic failures involve failure entirely within the ceramic. In some cases, the failure initiated in the ceramic, but propagated along the interface; these are designated ceramic to interfacial failures.

Figure 4 Plot of fracture strength versus duration of anneals at $1000^{\circ} \mathrm{C}$ in gettered argon, or in vacuum. The line is a least squares fit of all gettered argon anneal data. The four strengths measured for samples vacuum-annealed for $200 \mathrm{~h}$ were virtually identical; three failures were in the ceramic while one was interfacial. The average value is indicated by an open circle. These data were not included in the fit.

Figure 5 Comparison of interfacial microstructures a) before and b) after $200 \mathrm{~h}$ anneal in gettered argon.

Figure 6 Comparison of matching fracture surfaces for beams annealed 200 hat $1000^{\circ} \mathrm{C}$. The top and bottom rows correspond to the ceramic and metal sides of the fracture surfaces, respectively. The left-hand and right-hand columns are the argon- and vacuum-annealed samples, respectively. The bottom and top edges of the top and bottom rows of micrographs correspond to the tensile surface, and features "reflect" across this edge. A reaction layer is evident in the argon-annealed sample. 


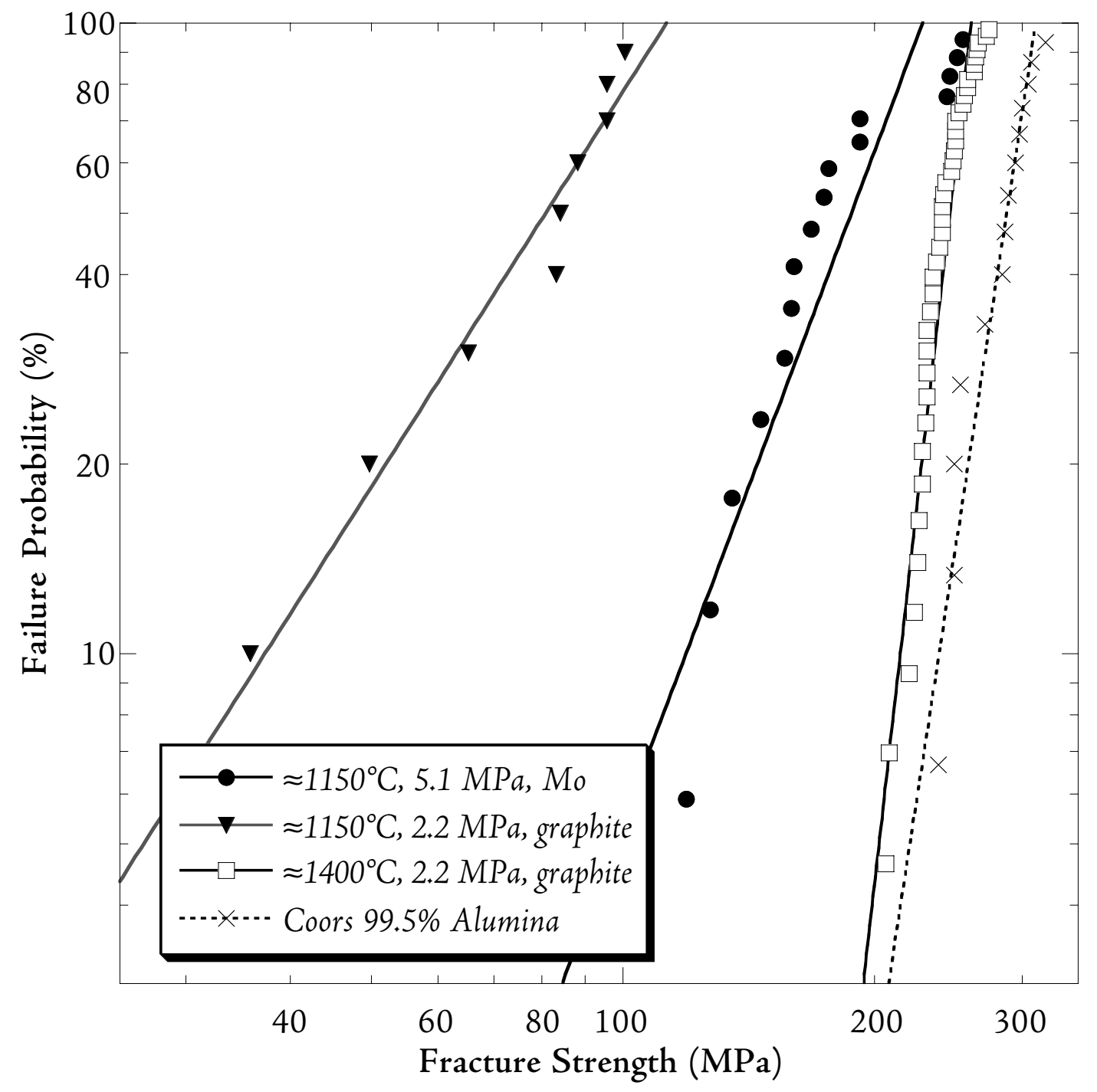

Figure $1 \quad$ Plot of failure probability versus beam fracture strength illustrating effect of processing conditions on joint characteristics. The alumina reference material was unbonded and not annealed prior to testing. 


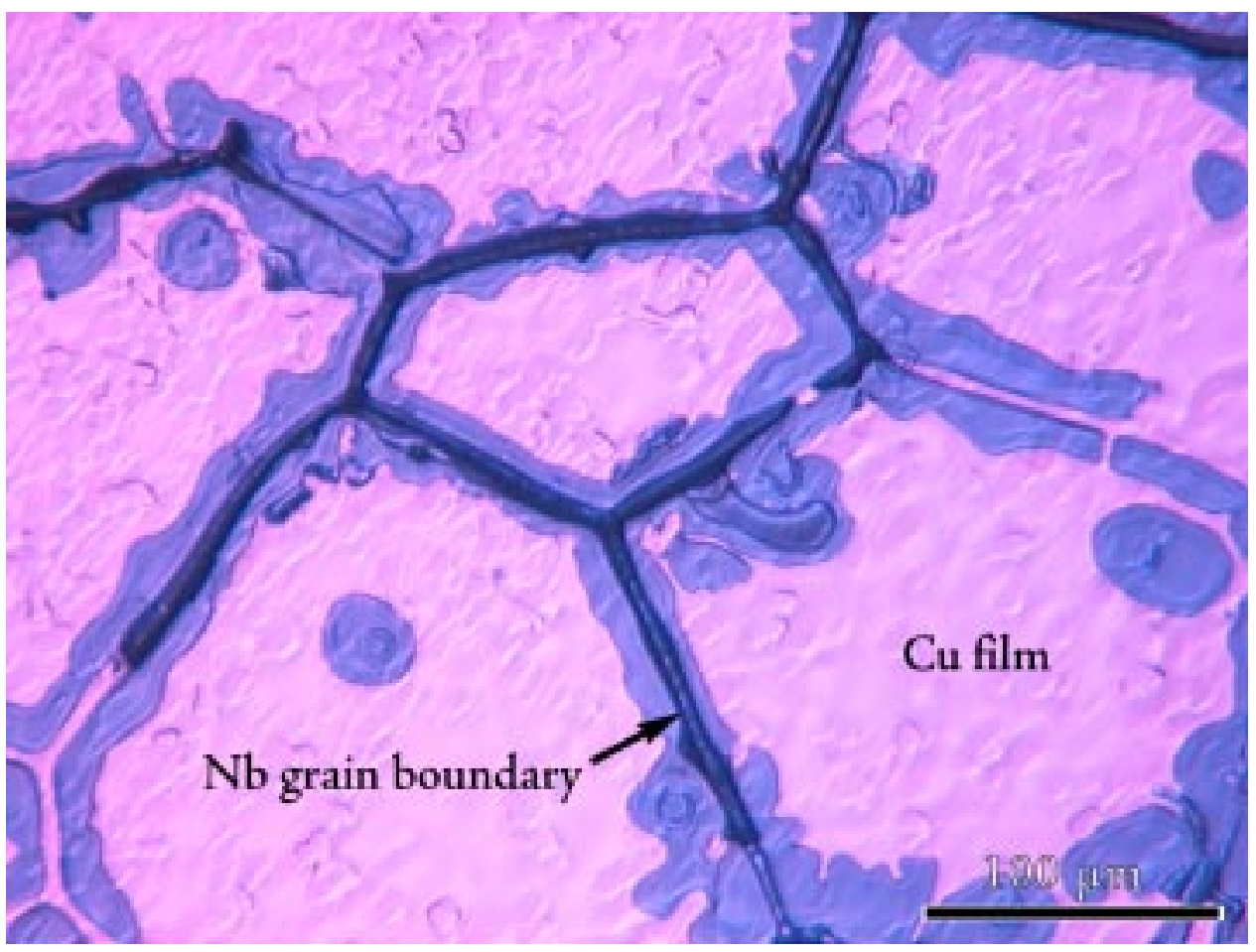

(a)

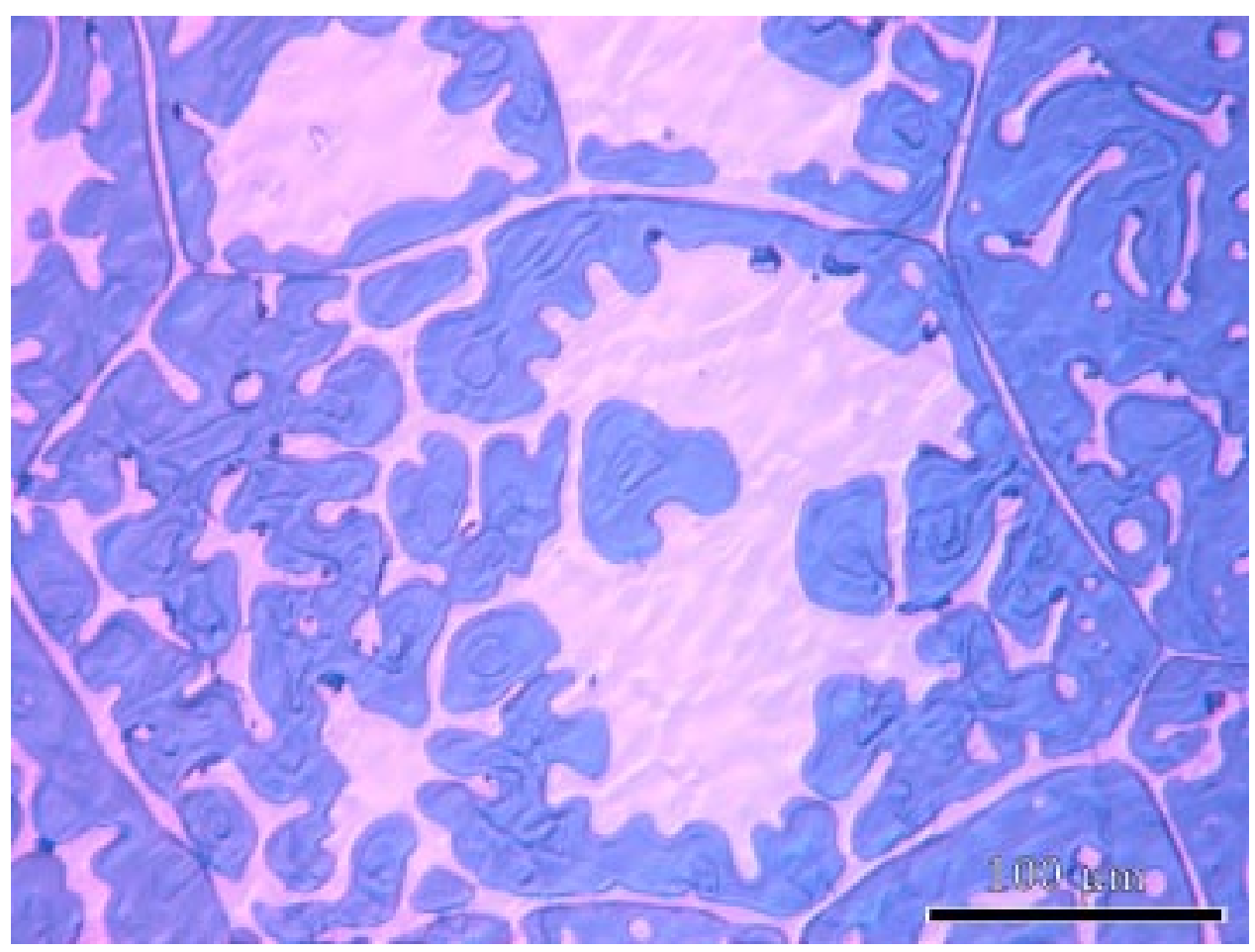

(b) 


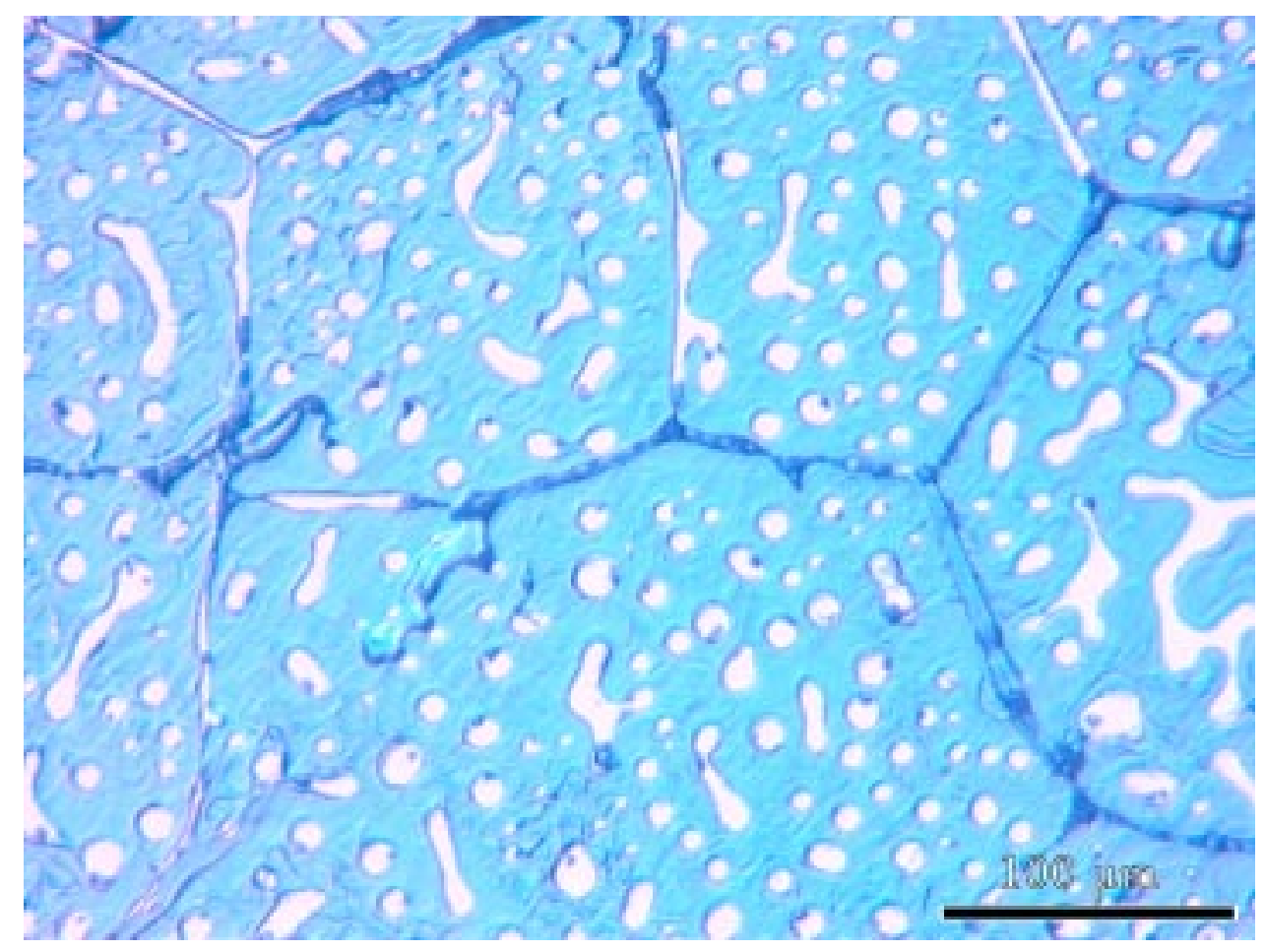

(c)

Figure 2 Illustration of interfacial microstructures in a sapphire/copper/niobium couple bonded at $1400^{\circ} \mathrm{C}$ showing possible sequence for microstructural evolution: a) initial niobium/sapphire contact along grain boundary ridges, b) regression and instability of isolated copper films, and c) regions of largely niobium/sapphire contact with small isolated copper droplets. 


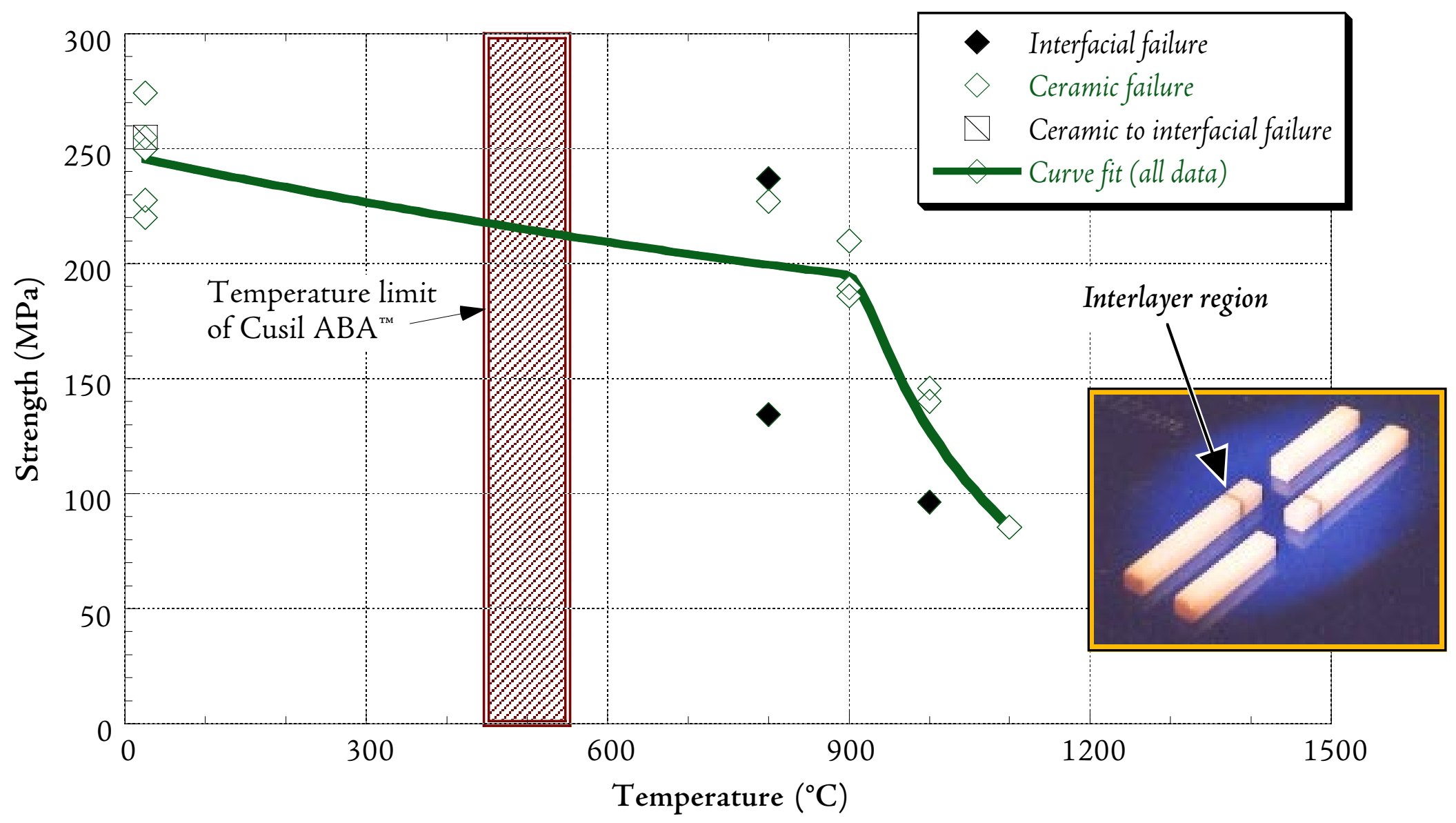

Figure 3 Plot of beam fracture strength versus temperature. Strengths are retained to high temperature, and instances of ceramic failure are observed in the $900^{\circ} \mathrm{C}-1100^{\circ} \mathrm{C}$ test temperature interval. The insert shows examples of some of the higher temperature fractures. Points characterized as interfacial failures correspond to samples in which the failure initiated and propagated entirely along the interface. Points characterized as ceramic failures involve failure entirely within the ceramic. In some cases, the failure initiated in the ceramic, but propagated along the interface; these are designated ceramic to interfacial failures. 


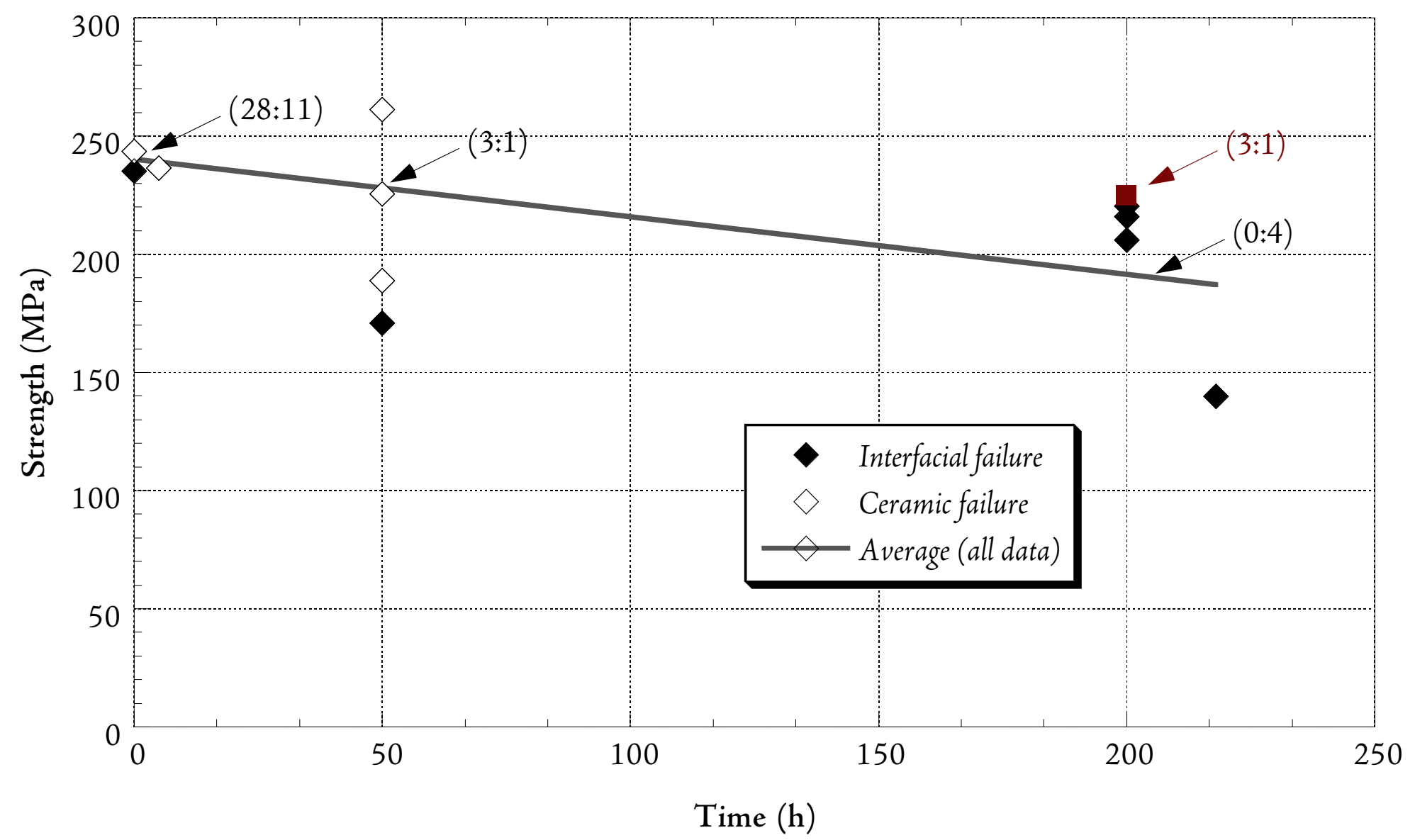

Figure 4 Plot of fracture strength versus duration of anneals at $1000^{\circ} \mathrm{C}$ in gettered argon, or in vacuum. The line is a least squares fit of all gettered argon anneal data. The four strengths measured for vacuum annealed samples were virtually identical. The average value is indicated in red ( $\square$ ). These data were not included in the fit. 


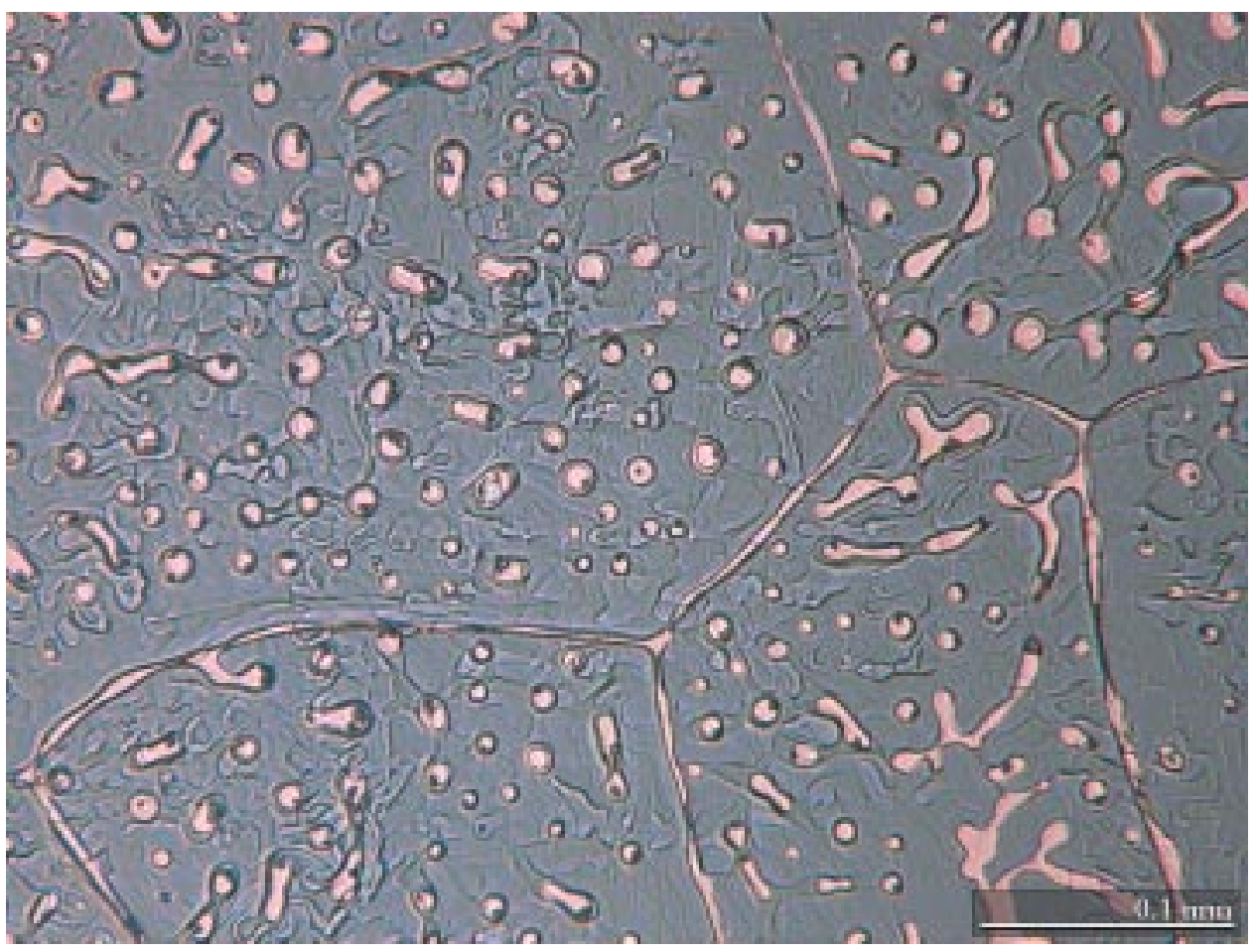

(a)

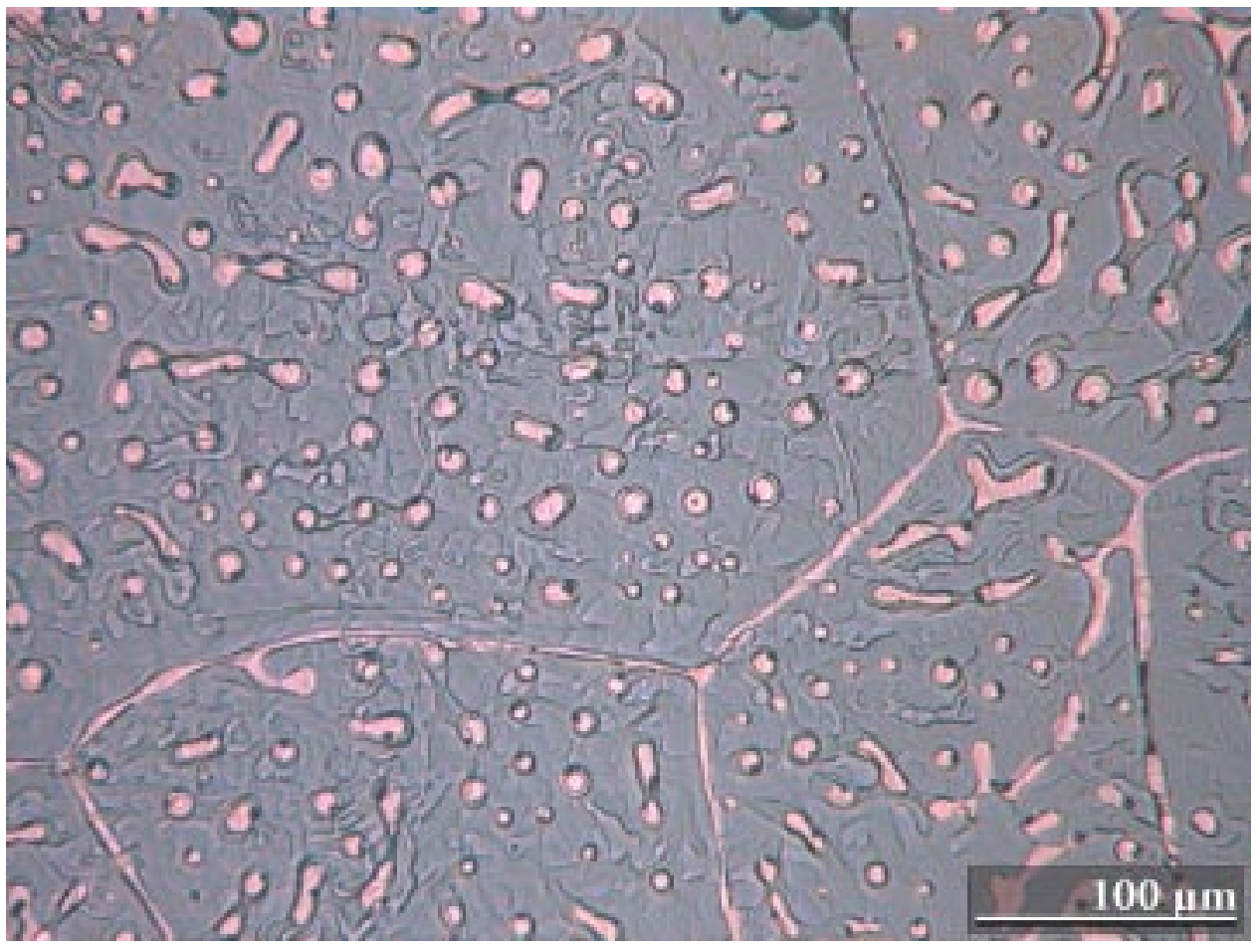

(b)

Figure 5 Comparison of interfacial microstructures a) before and b) after $200 \mathrm{~h}$ anneal in gettered argon. Few significant changes are evident. 

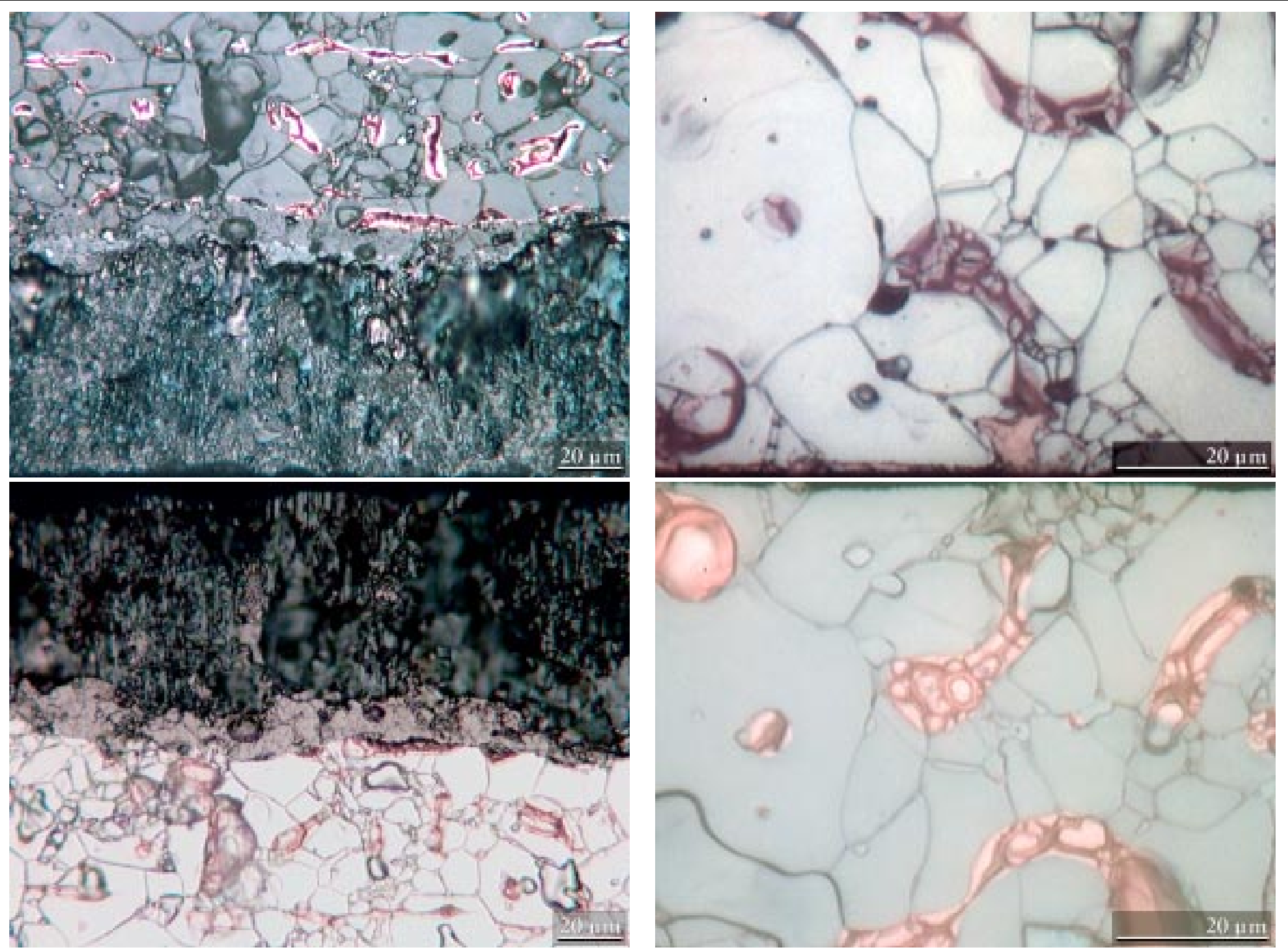

Figure 6

Comparison of matching fracture surfaces for beams annealed $200 \mathrm{~h}$ at $1000^{\circ} \mathrm{C}$. The top and bottom rows correspond to the ceramic and metal sides of the fracture surfaces, respectively. The left-hand and right-hand columns are the argon- and vacuumannealed samples, respectively. The bottom and top edges of the top and bottom rows of micrographs correspond to the tensile surface, and features "reflect" across this edge. A reaction layer is evident in the argon-annealed sample. 